\title{
Life after Wife Abuse: South Asian Women in the Greater Toronto Area
}

\author{
Anita Agrawal, B.Sc (Hons) \\ A thesis in partial fulfillment of requirements for the degree of Masters of Arts \\ Department of Sociology and Anthropology \\ Carleton University \\ Ottawa, Ontario
}

May 2010

(C) copyright

2010, Anita Agrawal 


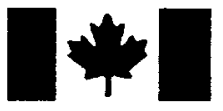

Library and Archives Canada

\section{Published Heritage} Branch

395 Wellington Street Ottawa ON K1A ON4 Canada
Bibliothèque et

Archives Canada

Direction du

Patrimoine de l'édition

395 , rue Wellington

Ottawa ON K1A ON4

Canada
Your file Votre référence
ISBN: 978-0-494-68692-8
Our file Notre référence
ISBN: $978-0-494-68692-8$

\section{NOTICE:}

The author has granted a nonexclusive license allowing Library and Archives Canada to reproduce, publish, archive, preserve, conserve, communicate to the public by telecommunication or on the Internet, loan, distribute and sell theses worldwide, for commercial or noncommercial purposes, in microform, paper, electronic and/or any other formats.

The author retains copyright ownership and moral rights in this thesis. Neither the thesis nor substantial extracts from it may be printed or otherwise reproduced without the author's permission.
AVIS:

L'auteur a accordé une licence non exclusive permettant à la Bibliothèque et Archives Canada de reproduire, publier, archiver, sauvegarder, conserver, transmettre au public par télécommunication ou par l'Internet, prêter, distribuer et vendre des thèses partout dans le monde, à des fins commerciales ou autres, sur support microforme, papier, électronique etlou autres formats.

L'auteur conserve la propriété du droit d'auteur et des droits moraux qui protège cette thèse. $\mathrm{Ni}$ la thèse ni des extraits substantiels de celle-ci ne doivent être imprimés ou autrement reproduits sans son autorisation.
In compliance with the Canadian Privacy Act some supporting forms may have been removed from this thesis.

While these forms may be included in the document page count, their removal does not represent any loss of content from the thesis.
Conformément à la loi canadienne sur la protection de la vie privée, quelques formulaires secondaires ont été enlevés de cette thèse.

Bien que ces formulaires aient inclus dans la pagination, il n'y aura aucun contenu manquant. 


\section{ABSTRACT:}

Based on in-depth interviews with fifteen South Asian women survivors of domestic violence and three counselors from South Asian Women's Organizations in the Greater Toronto Area, this project investigates women's experiences with the criminal justice system, social services, and community responses to domestic violence. This thesis identifies systemic barriers, constraints and challenges that South Asian women face when seeking social services following the experience of violence, by exploring their experiences with the legal system, shelters, Ontario Works (Ontario's social assistance program) and culturally-specific support services. After separating from their partners, South Asian women survivors face many challenges in accessing services such as social assistance and legal aid, which keeps them in a cycle of poverty. Housing and transportation also play an important role in determining women's access to resources. The gentrification of the Greater Toronto Area and suburban ghettoization of the poor, including South Asian immigrant families, affect women's mobility and contribute to their feelings of isolation and lack of community. By understanding women's personal experiences, this study contributes to the understanding of efforts to support women's empowerment, through a sociocultural and political-economic lens, and the impact of these efforts on individual women. The study also provides an examination of the areas in which wife abuse survivors need the most support. 


\section{ACKNOWLEDGEMENTS:}

In memory of Dr. Asha Goel and Dr. Robynne Neugebauer who were amazing and courageous women and always brought out the very best in the lives of the people they touched.

I would never have been able to complete this thesis without the guidance of my supervisor, Professor Jen Pylypa, whose patience and support has been relentless. She encouraged me to complete this even when there were so many times that I thought I was unable to. I would also like to thank my second reader, Professor Louise de la Gorgendière, for coming in to assist me at the pre-defense stage and encouraging me to 'get the ticket to move on with the rest of my life'. Also, a thank you to Professor Katherine Kelly for originally taking on the role of my second reader. Thank you to my mother and my friends for their love and support during several car accidents and many other challenges that I faced during the course of my writing. Most of all, I would like to thank the women who let me interview them, who invited me into their homes and shared their experiences and stories with me so candidly. Their courage and bravery are an inspiration to us all. 
Table of Contents:

CHAPTER 1: INTRODUCTION 1

Wife Abuse in Cultural Context 2

Wife Abuse in Political Economic Context 9

The Need for Culturally Sensitive Support Services for Wife Abuse 14

$\begin{array}{ll}\text { The Establishing of SAWOs } & 17\end{array}$

Constraints and Challenges Faced by SAWOs 20

$\begin{array}{ll}\text { Conclusion } & 23\end{array}$

CHAPTER 2: METHODS AND PROCEDURES 25

$\begin{array}{ll}\text { The Interviews } & 25\end{array}$

Recruiting Participants $\quad 26$

Respondent Characteristics $\quad 36$

$\begin{array}{ll}\text { Conclusion } & 40\end{array}$

Chapter 3: LIFE AFTER WIFE ABUSE 42

Types of Abuse $\quad 42$

Part 1: Cultural Expectations, Gender Roles, Marriage and Migration 44

Part 2: Work of the South Asian Women's Organizations 52

$\begin{array}{ll}\text { Counselling } & 54\end{array}$

Counselors' Experiences $\quad 58$

Part 3: Welfare, Employment, Housing, and Legal Aid - Women Living Under $\begin{array}{ll}\text { Neoliberalism } & 61\end{array}$

Ontario Works and Work Opportunities $\quad 61$

$\begin{array}{ll}\text { Housing and Shelters } & 68\end{array}$

$\begin{array}{ll}\text { Legal Aid } & 73\end{array}$

Part 4: Women's Current Social Situation $\quad 76$

$\begin{array}{ll}\text { Health } & 77\end{array}$

$\begin{array}{ll}\text { Living in Fear After Separation } & 78\end{array}$

$\begin{array}{ll}\text { Social Ostracism from the South Asian Community } & 81\end{array}$

On Moving Forward and Creating New Social Networks $\quad 84$

How to Make Improvements According to the Counselors and Survivors 89

$\begin{array}{ll}\text { Conclusion } & 90\end{array}$

Chapter 4: CONCLUSIONS AND RECOMMENDATIONS 93

Appendix A: Information Sheet sent to SAWOs and Distributed to Participants 100

$\begin{array}{ll}\text { Appendix B: Consent Form } & 102\end{array}$

Appendix C: Sample Interview Questions 104

$\begin{array}{ll}\text { Bibliography } & 109\end{array}$ 


\section{CHAPTER 1: INTRODUCTION}

Wife abuse has been a cross-disciplinary research topic of interest for the last several decades (Abraham 1995: 452). In particular, feminists have examined wife abuse largely through a strictly gendered lens that overlooks other areas of marginality and oppression. While some women of colour and black feminists have tried to re-situate wife abuse in a context that incorporates both gendered and cultural marginality (Gill and Rehman 2004: 76) by employing either an 'ethno-gender' framework (Abraham 1995) or an intersectional framework (Crenshaw 1994) they too also tend to overlook the macro structural and political-economic forces that may impact upon women's lives thus reinforcing or exacerbating their abuse while often reinforcing the importance of one level of marginality over the other (Thiara and Gill 2010c: 40).

In recent decades, socio-cultural anthropologists have advanced research to demonstrate how the impact of political-economic forces on the lives of individuals cannot be ignored (Farmer 2005: 30; Kleinman 2000: 226). Unfortunately, however, wife abuse has not been an area of interest for most of these anthropologists and gendered forms of violence are not given much attention by anthropology in general (Frederic 2005). As a South Asian woman anthropologist, in this study I examined the issue of wife abuse among South Asians in the Greater Toronto Area (GTA) through both an intersectional and political-economic lens. Having conducted qualitative interviews with 18 South Asian women in the GTA I examine how women experience wife abuse through a myriad of social, political-economic, gendered and cultural forces. 


\section{Wife Abuse in Cultural Context:}

According to a recent study by Raj and Silverman (2003: 435), over $40 \%$ of South Asian women living in the United States experience 'intimate partner violence,' that is, physical and/or sexual abuse. The researchers also found that most accounts of abuse were not reported, in part because $50 \%$ of the respondents surveyed were unaware that agencies that assisted abused women existed. Considering that the battered women's movement has drawn attention to violence against women for more than three decades (Abraham 1995: 455; Tjaden 2004), and given such a high rate of wife abuse within the South Asian diasporic community (Dasgupta 2000; Krishnan et al. 1998; Raj and Silverman 2003), why are so few South Asian women reporting abuse, and accessing support services for wife abuse? The most recent violence against women surveys in Canada unfortunately do not segregate wife abuse incidences based on ethnicity (Jiwani 2002a; Mihorean et al. 1999; Ogrodnik 2009). Given the support services available and the similar life circumstances of immigration to Canada and the United States (USA), we can hypothesize that there are similar numbers for South Asian wife abuse survivors in Canada. What economic, structural, social and cultural barriers do women encounter to successfully employ these services to escape violence and establish new and productive lives? What challenges do social service providers and wife-abuse counselors face in order to assist wife abuse survivors? This thesis attempts to address these questions.

A review of the literature indicates that culturally-sensitive services for South Asian women, who have experienced wife abuse, are abundant in metropolitan cities (Wachholz and Meidema 2000: 302). However, considering that many such support services have existed for over three decades, it is important to note that very little 
research has been conducted from the perspective of the women who receive these services. Originally, the intent of this thesis research was to explore women's own experiences of culturally-sensitive support services. During the interview portion of the study, it became apparent that it was important to broaden the main focus of the research to include women's general experiences with a myriad of support services, such as legal aid, law enforcement, and social assistance programs (known provincially as Ontario Works), as well as culturally sensitive support services. The purpose of this research thus became threefold: 1) to determine women's experiences with South Asian immigrant support services and other support services such as shelters, Ontario Works, Legal Aid, housing and law enforcement; 2) to find out how women are empowered to get out of abusive relationships and live on their own; and finally, 3) to assess what women felt were possible solutions to overcoming the shortcomings in the various support services that they accessed from the time of their separation/divorce to the present.

Since the experiences of women themselves determine the success of these services, by understanding their experiences we can contribute to a more holistic understanding of how to assist women in offering the best services possible and creating awareness so that those who have not yet accessed such services may be reached more effectively. Before exploring the voices of these women, this chapter discusses wife abuse in the South Asian and Canadian social, cultural and political economic contexts.

In recent years, anthropological interest in the 'violence of the everyday' has grown substantially (Kleinman 2000: 226). Wife abuse is a phenomenon that reflects this form of violence. Despite this burgeoning interest in the violence of the everyday, there has been an avoidance of discussing wife abuse per se in current anthropological 
literature (Friedric 2005). Anthropologists who do study violence describe violence as a normative process that is largely structural and institutionalized (Farmer 2005; Kleinman 2000; Singer et al. 1998). Much of the focus of their work has been around war, conflict, racism and poverty, and does not specifically focus on gendered violence such as wife abuse. Though understanding structural violence and other aspects of violence is necessary and relevant to women's experiences of violence, in order to theorize wife abuse, in particular, I must turn to various other sources and fields of academic literature. Many scholars who focus on domestic violence issues among South Asian immigrant communities in North America tend to focus on the patriarchal elements and 'cultural differences' (Goel 2005: 651; Jiwani 2006; Peacock 2003) of South Asian women as compared to Caucasian women. In both mainstream media and academic discourse it is far too easy to blame gendered abuse on cultural differences. Many highprofile cases in the media are sensationalized by positing that violence against women (VAW) occurs in the South Asian community, because of backward cultural practices such as arranged marriages, honour-killings, dowry and the non-acceptance of Westernized clothing (Jiwani 2006: 93). However, empirical evidence suggests that rates of abuse of women in South Asian countries are more or less the same as among women in North America (Bulbeck 1998: 122). Where the abuse rate is higher, though, is amongst the diasporic South Asian community (Raj and Silverman 2003: 435). This raises a critical question: could wife abuse in the South Asian diasporic community be exacerbated and facilitated by a combination of factors, beyond culture alone? This thesis suggests that other factors, relating to women's immigration status and the accompanying 
impoverished social networks, may contribute to this increase in domestic violence following immigration.

Since wife abuse occurs throughout the world regardless of women's cultural background, age, class, ethnicity or race, it can be understood using what Abraham describes as a social process within a feminist theoretical framework:

According to this view, wife abuse is not an act of deviance or a breakdown of the social order, but arises out of the very same normative structure that defines women as inferior, reaffirms dominance and aggression as positive attributes in men, and under represents women in all spheres of social, economic, and political life (Dobash and Dobash 1981 [cited in Abraham 1995: 451-452]). The dominance by men in heterosexual intimate relationships is seen as having its roots in the patriarchal values of society at large, mirrored in the legal structure. (Abraham 1995: 451-452)

From feminist theoretical frameworks, such as Abraham's description above, one can conclude that men as a group are socialized to maintain their dominant positions in patriarchal societies. Therefore, at the individual level, violence against women is a means for men to control and subjugate women. It is important to recognize, however, that such Western feminist frameworks have come under scrutiny by women of colour and black feminists for their lack of understanding of how women of colour experience violence (Crenshaw 1994: 94; Thiara and Gill 2010c: 29). Feminist scholars have long only examined VAW through gendered experiences, which can often replicate discrimination against women of colour while ignoring how other aspects of their lives “create both oppression and opportunity" (Thiara and Gill 2010c: 37).

To counter this one-dimensional view that VAW operates in strictly a gendered sense, in 1995, Margaret Abraham proposed a 'two-dimensional framework' called the 'ethno-gender framework' (1995: 452). This framework helped to examine how VAW 
operates in especially immigrant South Asian communities. Using this approach she suggests that wife abuse cannot be understood by examining it from a strictly gendered perspective, but rather one that takes both gender and cultural factors into account. In this study I expand upon Abraham's approach by incorporating an intersectional and political-economic framework as well.

An intersectional framework is an approach used to examine how women of colour experience oppression. This framework allows us to take into consideration a multitude of factors including race, sex, gender, class, cultural and political-economic forces, etc. (Crenshaw 1994: 94; Thiara and Gill 2010c: 36-40), to examine the experiences of South Asian women rather than just examining oppression in terms of solely gender or culture alone. Advocates of this framework suggest that it is a more holistic approach to understanding how women of colour (including South Asian women) experience violence (Thiara and Gill 2010c: 36-40).

There are many ways that cultural factors do play a part in how South Asian women experience wife abuse such as cultural expectations of a 'life-long marriage' and the adherence to traditional gender roles which require self-sacrifice (Goel 2005: 649). In most South Asian cultures, historically women moved in with their husband's family upon marriage, i.e., patrilocal residence. As such, upon marriage a couple might share a household with three to four generations of the husband's family members (Goel 2005: 649), occasionally with upwards of 15 other family members. These types of living arrangements are more commonly known as 'joint-families'. Joint-family arrangements are still common today in most parts of South Asia, however, they are beginning to erode in larger urban centres and among younger couples, who prefer nuclear family settings or 
who have migrated to urban centres for employment opportunities on their own (Ranga Rao and Sekhar 2002). For immigrant South Asians, the benefits and drawbacks of extended family networks are often absent, since many immigrate as individuals or nuclear family units.

It is evident from this study that men employ various strategies to control women. For example, emotional abuse, sexual abuse, psychological abuse, and economic abuse may, in fact, be part of an ongoing process that may/may not escalate to physical violence. The primary method of initiating this cycle of abuse requires isolating women from their close friends or family (Dasgupta 2000; McLeod and Shin 1992; Mehrotra 1999: 630). In this respect, this process of isolation is even more difficult for immigrant women as they may or may not have any family or close friends in their new country. Those who lack a support network, may experience higher rates of wife abuse than nonimmigrant women or immigrant women who do have family or friends in their new country (Dasgupta 2000; Mehrotra 1999: 626). However, it is worth noting that for women residing within an extended (often patrilocal) family, abuse against them may be conducted or incited by other family members as well their spouses (Mehrotra 1999: 627). Thus a "joint-family" arrangement that is common in South Asia can be both a source of abuse, and a protective factor that discourages abuse given greater access to social support. In this case, 'culture' plays a complex role, both protecting against, and at times exacerbating, wife abuse. Cultural influences need to be examined in a more nuanced manner, rather than simplistically as causes of violence. Or as Thiara and Gill explain, we need to examine: 
[c]ulture as a dynamic and contested force rather than as a static and unchanging monolith. It is thus both a source of oppression and support for women. Indeed, the central role of South Asian women, as part of diasporic communities, in reproducing and reinventing cultural values and norms as 'cultural entrepreneurs', has been noted by some writers (Bhachu 1993, p. 225 in Thiara and Gill 2010). At the same time, the expectation that South Asian women will guard and enact a version of 'culture' that perpetuates the interests of the patriarchal community, even if antithetical to their own interests has been recognised.

(Thiara and Gill 2010b: 18)

Though it is important not to resort to oversimplified 'culture-blaming', with regard to wife abuse among South Asian couples, researchers have noted that the particular form(s) that abuse takes may be culture-specific. For example, often husbands in South Asian households maintain control over women's finances directly (or sometimes indirectly by monitoring a joint account if a woman is employed) (Mehrotra 1999: 630). This may include monitoring the woman's expenses and ensuring that she does not make her own purchases, and/or controlling or seizing things that she does purchase. By harnessing control over women's purchasing habits and purchasing power, male spouses ensure that women are financially dependent on them, and/or can only spend money with their approval. Extreme forms of ensuring that women are financially dependent on their male spouses include destroying women's personal possessions and property, thus rendering them without resources (Mehrotra 1999: 630). Men also often compare their wives to other women in a negative way; this furthers women's feelings of inferiority and low self-esteem (Mehrotra 1999: 630). Men also resort to blaming their wives for events or incidences that go wrong in their lives, or events that are out of their control, which can include everything from their working conditions to how their clothes are not properly ironed (Mehrotra 1999). 
Though many social scientists have discussed methods by which men exert their control over women at an individual level, it is important to ensure that we do not treat women who experience wife abuse merely as powerless victims, as women express agency when they employ various coping strategies. Mehrotra (1999: 626) rightly cautions that it is easy to assume that women are only passive victims of abuse, so it is important to consider how women often resist their abuse in order to cope. Resistance strategies employed by South Asian women include secretly stealing money from the husband's wallet or cash box, not cooking for the husband or cooking certain foods that they do not like, not completing regular chores, ignoring or not talking to their husband (the 'silent treatment'), spitting into the husband's food, constantly nagging, and avoiding sleeping with their husbands (Mehrotra 1999: 631).

\section{Wife Abuse in Political-Economic Context:}

Over the decades there has been a mainstream obsession with trying to individualize and pathologize wife abuse. Many different theories have been formulated to account for the large numbers of women that are battered globally and within Canada. Theories such as "Battered Women's Syndrome" (McKenna and Larkin 2002) and others have largely focused on 'why women stay with their spouses' rather than focusing on how cultural and structural forces work in tandem to institutionalize and exacerbate violence against women (Bhanot 2002; Jiwani 2002b). Many of these theories focus on the individual men and women involved in the abuse and on the 'cultural' problems that bring about violent situations. As Desjarlais and Kleinman explain: 
Despite the many roots and implications of violence however, much of the medical and psychiatric literature on the subject focuses on individual welfare: on the psychiatric sequela of torture, for instance, or on the potential pathways to recovery for victims of violent trauma. While this focus is an understandable priority of psychiatrists and therapists concerned with improving the well-being of those troubled by violence, it has led us to pay less attention to the societal aspects of violence. It is clear that studies of violence and its consequences must go beyond the analysis of specific psychiatric symptoms to account for a range of social and political forces. (Desjarlais and Kleinman 1997: 1143)

The kinds of social and political forces that Desjarlais and Kleinman describe are examined in this section, and later in the interview analysis portion of this thesis. While much of the research conducted in the past has been limited to examining violence against women from an individualized perspective, it is important to acknowledge larger structural forces at play. How do state policy barriers, systemic racism and poverty act to impose a form of structural violence on the lives of women? The following section examines structural forces that affect the lives of South Asian women, including neoliberal economic policies, lack of recognition in Canada for migrants' educational and work training from abroad, legal aid, social assistance and employment as they apply to the lives of South Asian women abuse survivors. While significant strides have been globally made over the last few decades in Violence Against Women campaigns, like other social programs these campaigns and programs have become increasingly vulnerable to economic pressures. In many Western countries, the threat and onset of neoliberal economic and political shifts (Harvey 2005; Morrow, Hankivsky and Varcoe 2004) are forcing governments to retract and narrow the kind of funding they allocate to social and welfare programs. 
In the Canadian context, the idea that social entitlements (i.e., to adequate income, to shelter and to live free of violence) are important components of citizenship and equality is being undermined by neoliberal state values, expressed in federal and provincial policy shifts that favour self-sufficiency and economic competitiveness over a strong welfare state. (Morrow, Hankivsky and Varcoe 2004: 374)

Neoliberalism can be defined as an economic philosophy that favours privatization, and often has the effect of individualizing social and political issues while dismantling social welfare programs (Collier 2008: 19; Harvey 2005; Morrow, Hankivsky and Varcoe 2004: 359). In terms of the direct impact that neoliberal policies have on women's lives (i.e., abuse survivors), these policies involve cuts to social housing, legal aid, social assistance and welfare, an increase in state-sponsored police intervention initiatives, and a higher rate of criminalization of women (Morrow, Hankivsky and Varcoe 2004: 363). There are many examples of state funding being cut from British Columbia and Ontario (Morrow, Hankivsky and Varcoe 2004: 359). Under the neoliberal policy changes, keeping women's equality on the state's policy agenda becomes increasingly difficult. In the mid $1990 \mathrm{~s}$, the federal government altered its main social welfare funding policy to the provinces (Collier 2008: 20; Day and Brodsky 2007: ix; Morrow, Hankivsky and Varcoe 2004: 361). What was known federally as the Canada Assistance Plan (CAP) was split up into the Canada Health and Social Transfer (CHST) and other smaller provincial funds (Collier 2008: 20; Day and Brodsky 2007: ix). Under the CAP, provinces were given funding for social services such as legal aid and welfare under regulatory guidelines that legislated provinces to distribute funds to direct programs. However, under the newer CHST, funds were deregulated and the provinces could determine where funding would be spent without having to meet specific targets (Day and Brodsky 2007: x). This posed a certain challenge to women as Ontario's welfare 
policies altered substantially making room for workfare policies rather than direct social assistance and dismantling legal aid funding for civil cases (Day and Brodsky 2007: x; Morrow, Hankivsky and Varcoe 2004: 362).

While some researchers argue that neoliberal economic policies may not directly impact specific Violence Against Women programs (Collier 2008: 35), there are considerable data to suggest that, because women are generally poorer than men and are often relegated the responsibility of childcare, they are disproportionately affected by the consequences of neoliberal economic and social policies (Morrow, Hankivsky and Varcoe 2004: 365). Women, who have experienced wife abuse, significantly depend on the state for assistance in terms of phone help lines, legal aid, welfare, community counselling and advocacy; cuts to these programs, other than specific VAW programs, affect women.

Like the changes in the social transfers to provinces from CAP to the CHST, neoliberal policies have also made a huge impact on employment opportunities, where precarious employment is on the rise and where standardized worker's rights are decreasing as are the roles of unions (Evans 2007: 45). Under neoliberalism, employers are increasingly turning to hiring policies that offer the most work for the least cost. Women of colour, immigrant women and single mothers are vulnerable to such hiring practices due to the burden of their multiple productive and reproductive roles in both their own homes and in the larger society (Jiwani 2002b). Immigrant women especially have the added challenge of not always having their educational training or work experience from their countries of origin recognized. This forces them to take up jobs that 
are not in their line of training and do not offer substantial career or monetary benefits (Dhruvarajan and Vickers 2002).

In Ontario, workfare policies have been implemented in which individuals receiving social assistance must try to acquire employment while they receive social assistance (Evans 2007: 35). This leaves many wife abuse survivors left to face the difficult challenge of trying to secure work during their separation from their partners. Some researchers believe that social workfare policies are an indirect attempt by the government to ensure that low-paid employment opportunities are always filled and not overshadowed by social assistance payments (Evans 2007: 37) and under this scheme immigrants become the victims of precarious employment situations (Teelucksingh and Gallabuzi 2005: 5).

While it is not within the scope of this thesis to examine women abuse survivors' experiences pre- and post- implementation of neoliberal policies, it is difficult to dismiss the role that such policies play in creating structural barriers for South Asian women in their access to much needed resources such as full-time employment, recognition of their education credentials, housing and social assistance.

Naila Kabeer (1999: 461) suggests that women's empowerment is not solely about individual women's choices or agency, but also how a woman's choices are influenced by a myriad of structural and socio-cultural constraints. South Asian immigrant women abuse survivors not only bear the burden of gendered cultural expectations and impoverished social support networks in their new host country, but they also face systemic barriers regarding employment and social service acquisition. 
The Need for Culturally Sensitive Support Services for Wife Abuse

The process of getting out of an abusive situation is often a long, difficult and painful experience. Generally speaking, the process begins when women reach out to the police or local shelter service (Wachholz and Meidema 2000). Usually, some police intervention takes place and women are escorted from their homes with little to none of their personal belongings (Abraham 1995, 2005). For many immigrant women, police intervention can be a very intimidating situation; the police may represent negative experiences that women have had with the police or other such authority figures in their home countries or during their immigration process (Waccholz and Meidema 2000). After police intervention women are often taken to a women's shelter, which may or may not be close to their current residence. Shelters can often be overcrowded, isolating and depressing for women, especially for women of colour (Koyama 2006).

With very little of their personal belongings, women are often forced to start a new life on their own and choose separation from their husbands though they may do so with hesitation. This may require women to quit their jobs and relocate to a new neighbourhood. As others have noted:

In addition to creating barriers to work and diminishing women's physical and psychological well-being, domestic violence may also increase the risk of material hardships, such as homelessness, food insufficiency, and other economic problems. Women who are victims of domestic violence often have to decide between staying with an abusive partner and leaving sufficient shelter and food. (Tolman and Rosen 2001: 142)

If they are not employed during that time, women have to seek alternative means of income - which entails seeking out social assistance or welfare. However, seeking welfare puts women in another dilemma - in order to qualify for welfare they must prove that they have very limited funds. In Ontario, that means that they must have under 
roughly $\$ 1600$ in their bank account. If they have more money they must figure out what to do with it; this can often lead to women spending their money or giving it to their friends or family for "safe-keeping" (Agnew 1998b).

The next decision that women must make is if they can afford to hire a lawyer or not. If they cannot afford to, they have to wait on a list for Legal Aid Services. To qualify for Legal Aid Services, they need to once again prove that they do not have any income or savings, after which begins a process of determining whether or not there are any Legal Aid Lawyers available to them at that time. During this chaotic time women must also confront their husbands via the police, social service agencies, hospitals and courts. The whole process can take anywhere between three months and three years, depending on whether or not women qualify for certain social services or not. If women have children, it is an even more challenging scenario for them, as they must also factor in the needs of their children, including but not limited to their schooling, growth, adjustment and development.

One major reason that few South Asian immigrant women seek support for wife abuse is likely the lack of awareness of the existence of support services, as was found to be the case in Raj and Silverman's (2003) report, cited previously, where over $50 \%$ of South Asian women in their U.S. study were unaware that agencies that support abused women exist. This may be because mainstream agencies have not adequately addressed awareness of domestic violence in the South Asian community via reaching out to South Asian clients in their own cultural and religious organizations, or by providing adequate multilingual support and advertising, as noted by Gill and Rehman (2004: 76). Additionally, South Asian women's organizations are normally limited to only urban 
areas where a large South Asian population resides and thus can not support women in rural areas (Agnew 1998b). However, it is also important to acknowledge that there are other systemic barriers that prevent women from seeking out and receiving assistance. These will be explored in greater detail in Chapter 3 .

According to McLeod and Shin (1992), researchers for the Canadian National Clearing House on Family Violence, there are many factors that agencies need to take into consideration when they assist new immigrants, refugees and ethnic women who have experienced abuse as wives. These factors both limit visible minority women's ability to seek out help and also perpetuate fears among women who are already traumatized. The lack of competency in English or French is probably the most apparent barrier in such situations and presents a major limitation to immigrant women in Canada. Other factors include, but are not limited to: the stigma and silence around the problem of abuse (both within the South Asian community and mainstream communities); fear among abused women that they, their children or their spouses will be deported if they inform anyone about their abuse; the fear that their spouses will be imprisoned; the fear of ostracism from family and friends for divulging their private marital problems to authorities; fear that if a separation is inevitable, then they may lose custody of their children; and, lastly, women's fear that they will be unable to survive outside of marriage due to their limited language skills or limited or no work experience (Abraham 1995; Krishnan et al. 1998; McLeod and Shin 1992; Mehrotra 1999; Merchant 2000). Women may have experienced negative encounters with (sometimes racist encounters), with immigration officers, refugee officers, law enforcement officers and others (Krishnan et al. 1998; McLeod and Shin 1992), and employees of mainstream organizations who 
represent 'authority figures', and approaching these organizations for support may, therefore, intimidate women.

For these reasons and many others, South Asian women (many who were survivors of such abuse) responded to the growing concern of wife abuse by creating South Asian Women's Organizations (herein referred to as SAWOs) in larger diasporic communities in the UK, the USA and Canada during the 1980s (Abraham 1995; Agnew 1998; Gill and Rehman 2004; Krishnan et al. 1998; Merchant 2000; Peacock 2003). This thesis focuses on the work of the SAWOs, as many of the participants for this research were recruited through these organizations, and especially since many of the participants were also clients of these SAWOs for a considerable period of time (as discussed in Chapter 2).

\section{The Establishing of SAWOs:}

SAWOs are usually centered in cities with larger populations of South Asians. Nearly all of these organizations started as grassroots initiatives run by one or two women only (Abraham 1995; Agnew 1998; Gill and Rehman 2004; Krishnan et al. 1998; Merchant 2000). Some women operated SAWOs out of their homes initially, and some still continue to do so (Agnew 1998; Dasgupta 2000).

In addition to addressing some of the systemic barriers discussed previously, SAWOs ensure that they respond to their clients' needs in a culturally sensitive manner, primarily by employing (or acquiring volunteer) counselors from a similar ethnic background who are able to dispel South Asian women's fears and demonstrate that their experiences of abuse are neither "normal" nor a "taboo" subject to talk about (Gill and Rehman 2004: 80; Merchant 2000: 252). Cultural behaviours which may be received 
with cynicism or disdain by mainstream (i.e. non culturally-specific) agencies are accepted and understood by SAWOs (Merchant 2000: 252), in situations where immigrant women must cope with both patriarchal norms and values of both of the dominant mainstream and immigrant cultures (Abraham 1995).

SAWOs strive to support women, raise their self-esteem and help them determine their life course by offering a wide variety of services for women both at the micro and macro levels. Micro level strategies include, but are not limited to, providing: counselling, advice, and support; emergency contacts and hotlines; and, long-term resettlement programs (e.g., education and employment training, legal intervention, protection for women and their children, court accompaniment, supervised visits for noncustodial parents and translation services) (Abraham 1995; Agnew 1998; Dasgupta 2000; Gill and Rehman 2004; Krishnan et al. 1998; Merchant 2000). Macro level strategies include, for example: policy advising; immigration rights counselling and legal intervention; and, providing health care facilitators and agencies with information on how to treat women in a culturally sensitive manner (Abraham 1995: 462). Most importantly, the work of SAWOs aims to bring about social change by encouraging people to talk about wife abuse within the South Asian community and mainstream society. This is accomplished by distributing flyers in ethnic community centres/religious spaces, talking on TV and radio shows, providing fund-raising campaigns, and creating Internet resources (Abraham 1995: 465; Dasgupta 2000: 182).

Community campaigning is a task that is often met with great resistance (Abraham 1995: 464), especially by those in the religious community (Dasgupta 2000: 182), as the issue of wife abuse is sometimes considered 'normal' in some South Asian 
populations, while also a taboo topic that should not be discussed publicly. When women speak about their experiences of abuse it threatens the group solidarity in a culture where women are largely viewed as the 'gate-keepers of moral tradition' (Abraham 1995: 464; Dasgupta 2000; Krishnan et al. 1998; Peacock 2003). Additionally, in a society where cultural stereotypes about South Asians abound, South Asians may feel that it is important to preserve a certain reputation (Narayan 1990). Thus, if a marriage breaks down, or the family dissolves, women are blamed. Women are expected to sacrifice their individual identity to meet the priorities of their husbands, families, in-laws and community, and they must maintain and uphold the 'family honour' (Abraham 1995: 464; Krishnan et al. 1998; Peacock 2003).

It is important to note that not all SAWOs operate within a feminist framework. Some use a general framework, as described by the family violence theorists who conclude that abuse occurs at an individual level due to tensions between the spouses (Abraham 1995; Agnew 1998b; Crenshaw 1994). Family violence theory, however, is not a gendered framework, nor does it account for the significant difference between wife abuse and husband abuse (among other limitations of such an analysis) (Abraham 1995a; Tutty 1999). However, these SAWOs do provide support specifically for abused women. As Abraham (1995: 453) argues, however, that SAWOs largely employ an ethno-gender framework, as South Asian women experience patriarchal norms of both their ethnic community and the mainstream community. 
Constraints and Challenges Faced by SAWOs:

Aside from some of the above-mentioned intra-community challenges, structural challenges affect the very existence of SAWOs. SAWOs play a significantly important role in assisting women who experience wife abuse in their lives within the South Asian community in Toronto, Canada. However, because SAWOs are usually non-profit endeavours and heavily depend on the state for financial support, it is important to consider the role of the state, as it presents both opportunities and challenges to the overall functioning and governance of SAWOs.

Firstly, many theorists have argued that the terms 'abuse' and 'violence against women' must be expanded in the sphere of legislation and understanding to include other forms of wife abuse, such as sexual, financial, emotional, verbal and psychological abuse (Agnew 1998b, Mehrotra 1999; Tjaden 2004). Though individual counselors do their best to assist women who have experienced different types of abuse, the cases that they can actually accommodate are those that fall under a definition of abuse and violence that represents only extreme forms of physical violence. Therefore, only these cases are served by agencies and other forms of abuse are not addressed (Mehrotra 1999: 623). In its current socially accepted definition, the term wife abuse reduces complex heterogeneous interactions to one homogeneous social type (Mehrotra 1999: 623). This understanding is often employed by the state and creates a divide between worthy and non-worthy victims.

Secondly, feminist theorists caution that negotiations with the state should always be under scrutiny, as the state can present opportunities for intervention by NGOs in the formation of social policy and funding opportunities, but at the same time the state is 
often directly responsible for the oppression of women as it represents a patriarchal entity (Gill and Rehman 2004; Morrow, Hankivsky and Varcoe 2004). More specifically, because all SAWOs are predominantly dependent on government funding, by simply limiting their funds the state can hinder SAWOs' provision of needed resources, services, trained staff and, as I will demonstrate, it can even alter their entire working agenda (Agnew 1998a; Mehrotra 2000).

In the Canadian context, where the majority of non-profit organizations are largely funded by the government, the funding of NGO's is often uncertain from one year to the next which may pose a huge constraint on the NGO as to what services they provide (Agnew 1998a: 163). The cycle of events includes applying for funding, modifying working agendas, and garnering a positive response by funding bodies. In this process, the state as a funding body will only approve grants that are deemed useful, therefore SAWOs often have to include goals that are likely to be supported and viewed as a priority by the state. This often means creating programs for the larger South Asian community as a whole rather than exclusively for women (Agnew 1998a: 164; Merchant 2000: 258). Agnew (1998a: 158, 1998b) argues that even the term 'South Asian' can be seen in the larger political structure as a term adopted by South Asian agencies to garner funding from a state that does not recognize the differences and needs within the 'South Asian community.' The state uses SAWOs as cultural brokers that can facilitate addressing other issues in the South Asian community, and directs funds toward the services of SAWOs that include job training, language training and other programs, which diverts funds away from exclusively providing wife abuse-specific interventions (Agnew 1998a: 165). The expansion of services may seem to be complementary to the 
wife abuse counselling services of the SAWOs by offering services and programs that could enable women to acquire additional life, language and job skills. However, these services can also be seen to detract from their primary focus of assisting wife abuse victims (Agnew 1998a: 165, 1998b). Such expansion of externally funded services at SAWOs means that they are no longer obligated to serve women only; men are also permitted to acquire these other services as SAWOs become a 'catch-all hub' for the South Asian community. As a result, the SAWOs may no longer be perceived as a safe space for some women, as the expansion of services and activities may mean that abused women may unexpectedly encounter friends of their former spouses. SAWOs that are forced to expand their services also have to stretch their budget across services, without necessarily gaining any funding increases. This may force the redirecting of funds away from wife abuse specific programs. However, other researchers, such as Abraham (1995: 462), view the broadening of SAWOs services to provide other types of assistance as a benefit for women, since they help with issues such as legal assistance, escorting women to courts or doctors and helping women with immigration etc. Funding bodies also encourage applications that produce a higher turnover of wife abuse clients a year, even though many women take a longer time to recover from their traumas (Agnew 1998a). This fits in with the state's neoliberal policies and encourages women to move quickly into the work force even when they may not be in the mental, financial or physical position to do so. 


\section{Conclusion:}

This study examines how SAWOs, the government and other social service providers meet the expectations and needs of clients, and their degree of success in fulfilling their mandates and addressing impediments to doing so. The state plays a role in affecting the work of SAWOs through setting priority areas for funding that forces SAWOs to expand their efforts beyond services for abused women to a variety of other community services. An ethnographic approach facilitated examining these issues from the client's perspective. As Naila Kabeer (Kabeer 1998, cited in Gill and Rehman 2004: 79) argues, it is necessary that women fully participate in the decision-making process in order to achieve genuine development and empowerment.

This thesis contributes to a more holistic understanding of how some South Asian women in Toronto experience life after they have been subjected to wife abuse and decided to leave their husbands. By learning from women who have used, and are currently using, SAWOs, shelters, legal aid and Ontario Works' facilities, we can open up opportunities to find out how to better serve their interests and how to better facilitate outreach programs in the community. Gill and Rehman (2004: 80) also argue that the work of SAWOs and the state must be constantly monitored and revisited in order to see whether the needs of women are being met, and if women truly do feel empowered.

This study also contributes to furthering knowledge about feminist consciousness and empowerment models of counselling practices, or the lack thereof, in SAWOs. As noted earlier, some agencies do not facilitate feminist counselling practises. Preliminary investigation indicates contradictory positions assumed by researchers in this area. Crenshaw (1994) argues that counselling practices are positive for women, as they are not 
grounded entirely in feminist models of therapy and thus counselors focus more on immediate and practical concerns of women. However, Agnew (1998b) states that feminist models of empowerment are essential for long-term therapeutic benefits to women, and by not implementing them, some counselors may actually encourage women to follow patriarchal norms and practices without question (Agnew 1998b).

This work is relevant to anthropology, because it encompasses many issues that are pertinent to our understanding of power dynamics, civil society, violence of the everyday, health and wellbeing, gender and culture. More specifically, it helps to understand how social welfare policies affect individual women. Paul Farmer explains the anthropologist's role in facilitating how macro level processes affect individuals:

Anthropologists and others who take these research questions study both individual experience and the larger social matrix in which it is embedded in order to see how various social processes and events come to be precisely translated into personal distress and disease. By what mechanisms precisely, do social forces ranging from poverty to racism become embodied as individual experience? (Farmer 2005: 30 emphasis in original)

Studies of South Asian women's experiences of wife abuse are limited, especially within the Canadian context, and studies of how South Asian women view support services are also limited. This thesis contributes to a better understanding of both of these issues. 


\section{CHAPTER 2: METHODS AND PROCEDURES:}

This chapter offers a detailed look at the respondents, recruiting method and interview process. In a qualitative research study on a sensitive topic such as this, it is important to address the methodology and method of recruitment for both ethical and academic reasons. In this chapter, I will give an overview of the interviews, the method of recruitment and more detailed information on the participants.

\section{The Interviews:}

I conducted semi-structured interviews (see Appendix C) with 18 South Asian immigrant women in the Greater Toronto Area. Of the women that were interviewed, 15 were wife abuse survivors and three were counselors. While providing some necessary structure in order to initiate discussion, the semi-structured interview method allowed me to expand our discussions, because questions were not necessarily asked in any particular order and largely depended on the rapport established between myself (the researcher) and the participant. Using the semi-structured interview method allowed me to loosely group questions into categories based on the following categories: family background, immigration experience, social support networks, current living situation, access to services, gender roles, use of support services, service needs, empowerment and future goals. Thus, my approach balanced structure and flexibility. This is in keeping with qualitative research methods as "[q]ualitative methods tend to be nonlinear and support the notion that each individual's experience, especially her social reality, is shaped by social context: culture, historical time, and position" (Hunjan 2003: 67). 


\section{Recruiting participants:}

In order to recruit participants, I contacted several South Asian community organizations that offer, but are not limited to, counselling and other services for women who have experienced wife abuse. In the Greater Toronto Area (GTA) there are about six such agencies that deal directly with the issue of wife abuse, of which three have considerably greater resources and more clients than the others. In addition to their services for wife abuse survivors, these organizations provide invaluable resources and services to the South Asian community in the GTA. Such services include mental health services, immigration support, legal aid connections, English as a Second Language (ESL) classes, networking opportunities, job training sessions and counselling for abused women. The functions of these agencies are similar to those in other countries, such as the United States and the United Kingdom (Abraham 1995: 460-465; Gill and Rehman 2004: 78).

As the issue of wife abuse is one that is of a very personal nature, I thought it would be far more effective for me to recruit participants directly through the three larger South Asian family agencies than to try to recruit participants by phone, advertisements, or community or religious centres. Trying to recruit individuals for this study independently would also mean a huge time investment, which is not feasible for a Master's level thesis. Many of the smaller organizations are limited to specific languages, and I am not fluent in all of those languages. Taking into consideration the nature of my study, the method of recruitment might entail some bias. In addition to this type of recruitment, I also used a snowball sample where women either contacted their friends to be interviewed or gave me the contact information of women who might be interested in 
this study, broadening the scope of interviewees. Using this method of recruitment also helped me to establish familiarity and credibility with the participants as it was assumed that because both the agencies and/or their friends knew about me that they could trust me. Trust was a very crucial component to the recruitment process and as one woman relayed to me after one information session: "I am not amused [sic] by your research. I will let you interview my friend first, and if she thinks you are okay - I will participate."

When I contacted the three agencies, I provided a written summary in which I stated my interest, provided my university's contact information and listed the goals of my study. The first agency that I contacted seemed to be promising, however, with time I was unable to maintain regular communications with that agency and slowly they stopped responding to my requests to schedule volunteer and client recruitment time. I was aware (from my past interactions with this agency) that this agency was understaffed and overworked, so I offered to volunteer as an administrative supporter on a weekly basis for the duration of my research. I assumed their lack of arranging interview sessions with their clients was due to the overwhelming constraints that non-profit organizations face; i.e., they have few resources and a burdensome workload. However, after a few more attempts to contact this agency via phone and email, I decided to refrain from contacting this agency as I did to want to burden them.

When I contacted the two other agencies they were very supportive and one of them arranged to schedule a meeting with their clients right away. This was in February of 2006. This agency (Agency A) invited me to come in and speak with their clients at a meeting they arranged specifically for me. I arrived at the agency and was asked to make

\footnotetext{
${ }^{1}$ Later, I decided not to contact this woman for an interview because her friend advised against it due to the woman's ongoing family problems.
} 
a small presentation about my project. There were about 25 women and a few children in attendance. In my presentation, I introduced my project, assured the women that participation was voluntary, that they could contact my university if they wanted to, and that everything was confidential. During the presentation I passed around a take-home handout for the women, as well, which mirrored what I was presenting and had my contact information, and my supervisor and university's contact information (Appendix A). Of the 25 women that attended this information session, 10 of them wrote their phone numbers and contact information in a notebook that I passed around during the session. While this recruitment method did not allow for complete anonymity amongst the women present that day, it was the easiest method of recruitment and was suggested by the counselor herself. This allowed the women to feel more comfortable with me as a researcher and established a sense of trust between the agency, the clients and myself. I also offered the women an honorarium for participation - which was $\$ 15$ plus $\$ 5$ for transportation, which I subsequently increased to $\$ 25$ after I started the interview process and came to know of the women's financial constraints.

One of the clients of the agency preferred to have the interview conducted on the premises immediately, so I conducted the interview in a separate room that the counselor provided for me. The woman was very comfortable and talked candidly with me as the door was closed and there were no occupants in the adjacent rooms. Though many women were keen for me to interview them immediately after the presentation, I could only interview one of the women that afternoon. Some of these women made immediate arrangements to meet with me again. For the other women I distributed my contact information and made arrangements to meet with them outside of the agency. The 
interviews that happened from recruitments at this agency occurred between February and April 2006.

At the third organization that I contacted (Agency B), I arranged for an interview with their main wife abuse counselor, who has nearly twenty years of experience counselling women. When I met with the counselor, she was not too keen to provide me with access to the clientele, however, she said she would pass on my information script to her clients if they were interested. She told me, “These are Indian women; they don't want to talk about these things." I left some of the same handouts with her as I had given to the other women in attendance at Agency A. For awhile I did not hear from Agency B, until one day the counselor invited me to an 'empowerment workshop', three months after the interview, in May 2006.

Agency B's workshop was held primarily for clients but also other service providers such as interpreters and translators of clients, ESL teachers, agency staff members and others. This session was a unique opportunity because it also allowed me to participate and actually attend an 'empowerment' session for myself. At this session, the counselor encouraged each woman to talk about her experiences, and how she overcame the challenges and abuse that she faced in her life. The overall experience was very emotional for me, and from what I could tell, for the other women in attendance. To hear women's stories directly, to see that so many women had empowered themselves and were brave enough to share their stories with virtual strangers had a deep impact on me. The counselor also made a presentation about what it means to be empowered and what empowerment was in different South Asian languages. By doing this she made women realize that empowerment is definitely an aspect of South Asian culture, too. She used 
various sources like newspaper articles, social work articles, statistics and other personal stories in her presentation to provide motivation for the women in attendance. In addition to the presentations made by the counselor and the women, there were some stress relief and yoga technique presentations.

The counselor at this agency also spends time collecting new and used clothing for her clients. In a large room she had arranged many items of clothing by categories into piles so that the women could choose clothes that they needed. Within minutes nearly all the clothes were gone. In an interview prior to this session this counselor, Shilpa ${ }^{2}$, had told me, "I arrange for clothes for these women because often they leave their house with nothing else but themselves and their children. They can't usually afford to buy the latest fashions, and sometimes the simplest things can make a difference in their self-esteem" (February 16, 2006).

In this session the counselor, Shilpa, permitted me to give a brief presentation to recruit more women for this study. After I made this presentation, five more women volunteered to be part of the study. Though I had already recruited over 10 participants from the first agency, a social worker friend of mine had informally advised me that each region in the GTA had a different South Asian constituency, i.e., everyone was ghettoized according to the region of South Asia they were from. Therefore my friend suggested that I should diversify the agency recruitments a little more, by targeting agencies in different parts of the city. After I conducted the interviews I realized that my friend's suggestion was indeed correct and my new participants were from different parts of South Asia. The interviews with women from this agency took place in May 2006.

\footnotetext{
${ }^{2}$ All names used in this study are pseudonyms.
} 
As an Indo-Canadian (someone born or raised in Canada of Indian descent) researcher, there did seem to be some benefits of my social position in terms of my ability to conduct this study. Though most of the women spoke English, it was beneficial to the study that I spoke fluent Hindi. Being able to speak fluent and colloquial Hindi allowed women to feel comfortable around me. Among survivors with whom I shared a similar cultural background there was a sense of familiarity and they spoke to me often with the assumption that I understood a certain situation or cultural practise. In places where I did not understand or where appropriate I would probe them in order to avoid making assumptions. As I was a younger, single, unmarried woman, this also helped women to feel comfortable around me. Since marriage is a huge rite of passage in the South Asian community and women are often afforded a higher status due to their marital situation, my status as a single woman became a point of solidarity for many women and this allowed them to joke very candidly with me about not getting married, as most of the women themselves were single. Despite their varying backgrounds (age, region, religion, experiences with abuse and education) there did not seem to be a difference in the very candid and comfortable manner in which women talked about their experiences.

During the interviews, I never asked the women any questions that directly pertained to their experiences with wife abuse itself (Appendix C). I avoided asking such questions because I did not want to retraumatize women who were volunteering sensitive information already. Initially, I was hesitant to talk to women about their direct experiences with abuse. However, women raised the situations they were in by themselves, as many women felt it was necessary for me to understand where they had been so that I could get a better idea of their lives. Where I felt women needed some 
comforting or where it was appropriate I did talk to them about my own experiences with family violence. In order for me to better understand their situation, some women even had newspaper clippings, photographs, and court papers ready well before I arrived to interview them. They would share these things with me very openly, and they expected that I would listen to them.

Individual women made statements such as, "If I knew what he was like before now, I would not have ever been involved with him. I want to warn other women not to put up with this type of behaviour." (Farzana, February 22, 2006). Other women cried when relating their hardships, "I can't believe I have had to live such a hard life, while others enjoy theirs" (Rita, February 28, 2006). Others allowed me to look at their court transcriptions if I liked, but they did not want to verbally retell their stories to me and would say things like, "You won't believe the things I have been through" (Nilam, February 22, 2006). I did my best to acknowledge and respect the women's comfort levels when they told me their stories of the abuse they experienced. Occasionally, the retelling of these experiences resulted in the participant being very emotional and often crying. Sometimes, it was difficult for me to control my own emotions, too.

Though many of the counselors and the literature I had read prior to my interviews warned that I would have a very hard time getting women to 'open up' about their experiences, I found that once I actually started the interview process the opposite happened. I asked one of the counselors if she felt I might be re-traumatizing the survivors by conducting this study. She responded by explaining to me: 
No, no that is not true. I think the more women they talk to - the more people they talk to - the more strength they get. They get an insight about. For example, if you see a person that is not really perceptive to what you are saying, if she is ridiculing or if she is criticizing them - or giving them suggestions, then it could be harmful. But if you are letting them talk - I think it's very therapeutic. (Megha, counselor, February 8, 2006)

After I started conducting my study, I found that the women were very keen to talk to me, and many of them would refer me to their friends. Individual women made statements such as, "I want people to know my story" (Alpana, February 20, 2006), “Other women should learn about what happened to me and that it is common" (Rita, February 28, 2006). One woman even told me that, "I am really glad that you are doing this research. If you hadn't I would have done something about this, and I still just might"3 (Farzana, February 22, 2006).

These responses helped me at a very personal level. At many times, I felt as though I was 'using' the participants and that I wasn't contributing towards helping them, and that I may even be retraumatizing them. As academics we often hear frontline workers comment how we aren't really helping when we conduct our research. As one counselor told me informally, "Well you know how these academic studies go - someone does them but then who listens to them? They may get published but no one really reads these things" (Megha, February 8, 2006). In my case, I felt as though I was getting an MA degree out of my research yet, how was I really helping these women? Learning that many of the participants felt that the interview was a positive experience for them helped me to appreciate their comfort levels, and alleviated some of my initial hesitation around conducting this type of research. Some of the survivors referred other women to me, and

\footnotetext{
${ }^{3}$ This participant wanted to conduct a project that involved collecting the stories of wife abuse survivors.
} 
stated that they thought this type of research allowed them a voice - which was very reassuring for me.

At the time of my interviews many of these women were living below the poverty line and many of them were receiving government funded financial assistance. Many were living in government-subsidized housing, and some lived in the same building complexes. After my recruitment was complete from Agency A, I also mailed the counselor(s) that I had interviewed a small gift and made a donation to the organization of $\$ 100$. Neither the gifts nor the donation was discussed prior to the recruitment process, to ensure that this did not influence the recruitment of women participants for this study.

In most cases the interviews were audiotaped. Only three interviews were not tape-recorded, due to the women's preference or logistical constraints. Women were very aware of the presence of the recorder. For example, on occasion an individual woman would stop the recorder and say, "I would like this to be kept off the recorder, but I want to tell you this." In some instances when women would be casual with me and ask me questions about my life, they would say, 'You don't want to tape that, you already know that about yourself.' Although the conversations were informal, the fact that I was the interviewer never escaped the attention of the women. My presence as a researcher was always there.

Nearly all interviews with the clients of the agencies took place in the woman's place of residence. This served multiple purposes; it was for their comfort level, allowed for a place that was private, and also because many women lived in areas where public transportation was not convenient. There was only one interview that I conducted by phone. Initially this woman inquired whether I knew of a 'spy' (private investigator) or if 
I was a spy myself. I asked her why she was seeking a spy, and this woman told me that it was because she wanted one in order to investigate her husband. This woman was a survivor of a very high-profile case, in which her husband had recently attacked several of her family members. Since the crime was very recent, I felt more comfortable interviewing the woman by phone, for my own safety. In order to receive her consent, I had mailed her two copies of the consent form and enclosed a self-addressed envelope so that she could send me back the one she had signed.

In all the cases where women had children, the children stayed home as well during the interview sessions, even if it was a weekday. This initially surprised me, but it seemed to be a fairly common pattern. I never inquired as to as why this was the case, but I am assuming that this provided the women with a sense of comfort to have the children at home when they were interviewed by me. None of the women I talked to had been interviewed for a study like this before. On two separate occasions women wanted to have a friend accompany them when they were interviewed; at these times I took the opportunity to interview both of the women (in both cases the other women were survivors who met at the same agency for assistance - Meena and Kruti and Nancy and Veena). Since the women's friends were already present when I arrived and they indicated that they were comfortable with their friend, I interviewed them in the presence of their friend. This may have impacted their responses to either increase their comfort level with me or it may have also worked to limit their responses. It is difficult to tell, but their responses seemed fairly unrestricted.

Prior to the formal part of the interview I reviewed the information script and consent forms (Appendix B) with the women and asked them to sign and date the consent 
forms. In some cases the women were more comfortable speaking Hindi in which case the interview was primarily conducted in Hindi. For my non-Hindi speaking participants the only option was to conduct the interview in English. Most of my participants had a working knowledge of English, though English was not their first spoken language. ${ }^{4}$

The three counselors were always interviewed at the place of their work; due to their busy work schedules, this proved to be the most convenient choice for them. Two of the counselors had closed office spaces, and one of the counselors was a junior counselor, and she was interviewed in a closed room provided by the agency. The interviews with the counselors were all audio-recorded.

\section{Respondent Characteristics:}

The Greater Toronto Area (GTA) includes the regional municipalities of Durham, Halton, Peel and York. It is estimated that the GTA has the largest South Asian population in Canada and that that number is well over 700,000 people or $13.5 \%$ of the population of the GTA ${ }^{5}$. With the GTA having the largest South Asian population in Canada, it seemed ideal to conduct a study about wife abuse, counselling and South Asian women in this area.

Although South Asians do not represent a homogeneous community, some researchers (Peacock 2003) argue that enough cultural similarities offer legitimacy to this collective name. Others, however, are not so keen to adopt its usage because it is a term that is often used solely on the basis of the geographical proximity of 'South Asian' countries, without regard to the large religious, cultural and linguistic diversity of the people (Agnew 1998a). To clarify, I use the term 'South Asian' as it is used by SAWOs,

\footnotetext{
${ }^{4}$ With the exception of one woman who was from the West Indies.

${ }^{5} \mathrm{http}: / / \mathrm{www}$.thestar.com/Canada/Census/article/409455
} 
that is, an umbrella term to define immigrants who come from India, Pakistan, Bangladesh, Sri Lanka, Nepal and Bhutan, and also their descendants who have doubly migrated from the West Indies, Fiji, and Africa, among other areas.

There are many ways to denote the term 'wife abuse,' though many researchers use the following terms interchangeably: wife assault, domestic violence, intimate partner violence and family violence. In the course of this research, I use the specific term 'wife abuse', as the focus of this study is on women who are/were married while experiencing abuse. 'Wife' is a term that is gender-specific, one that is politicized and acknowledges that wife abuse is a societal problem. Also, the term 'abuse,' as it is used here, is not specific and encompasses all forms of abuse, thus is not limited to only the physical, emotional, psychological and sexual abuse, which constitute the four traditionally acknowledged forms of abuse in academic discourse (Mehrotra 1999). Other common types of abuse that wife abuse survivors face include: financial (restricting or monitoring one's funds), spiritual (using religion as a strict code or not letting one practise their faith), and isolation (neglect or not allowing women to interact with others) (Abraham 2000; Mehrotra 1999: 633).

For the personal security of the interviewees, I choose to generalize aspects of their identity related to their ethnicity, religion, age, and occupation. The age range of the women survivors that were interviewed was $34-58$ years. The religious backgrounds were also varied; I interviewed women who were Hindu, Muslim, Sikh, Buddhist and Christian. Their ethnic backgrounds were also varied and the women's countries/regions of origin included Bangladesh, India, Pakistan, the West Indies, Sri Lanka and Africa. While there was one person who was born and raised in Canada, the remainder of my 
interview participants had lived in Canada for the last four to 35 years. Although some of the interviews were conducted in Hindi, all of the participants had a working knowledge of English and all but two were completely fluent in English in addition to their native language. With the exception of four of the participants in this study, the majority of the women had at least one child, and none had more than two. Of these women two women had children who were older and not residing with them, while the majority of the children were under 12 years of age, and were living with their mothers. The age range of the three counselors that I interviewed varied as well - from 25 to 55 . Their ethnicity and religious identities also varied. Only three participants were living with their spouses. One was living with her new husband, one with the abusive husband, and another was undergoing divorce proceedings and shared accommodations with that husband for the time being ${ }^{6}$ until the divorce proceedings were over.

All but one of the participants that I interviewed had completed a minimum of high school in their countries of origin. The majority (12 out of 15$)$ of the participants in this study also had a post-secondary education. Their educational experiences and areas of interest varied considerably. These women had university degrees in the social sciences, biological sciences, physical sciences, law, business, health, education, administration, computers and social work. Many of the women had certificate training from Canadian colleges in addition to their education from their countries of origin. One of them had training from the USA. Four of the survivors had post-graduate degrees.

Most of the women migrated because of their husband's decision to move to Canada. As such, their husbands sponsored these women. A few exceptions to this included one of the women, Salima, who sponsored her husband a few years after she

\footnotetext{
${ }^{6}$ This woman has since then moved out from her husband's home.
} 
moved here when her sister sponsored her. Another woman, Chandrika, said that she and her husband moved to the USA because she was accepted to a doctoral program there. Later she moved to Canada, without completing her education (because of her husband's abuse and infidelity), and he followed her here though they were separated at the time of her move. Another woman, Kruti, moved to Canada with her husband to provide a better life for her son and also to advance her own professional career.

Only three of the participants that I interviewed did not have Canadian work experience, and all of the others had worked in Canada at some point. Most of the women who had Canadian work experience, coupled with post-graduate education from their country of origin, did not have Canadian work experience that was directly related to their training. This is a problem that many new immigrants face when their degrees are not recognized in Canada. This is discussed further in Chapter Three. A small number of the survivors had work experience from their countries of origin. Despite their work experiences, only four of my participants were currently employed, while many of the others were on social assistance. Out of the women who were employed, only one had a full-time permanent job; many, unfortunately, were working in low-paying jobs with irregular work shifts. The three counselors interviewed were all employed at the time as full-time staff.

The types of marriages that the women entered were largely some form of 'arranged marriage', however, there were at least four participants who had met their spouses through a 'love-marriage'. In these 'love-marriages', all of the women had courted their spouses against the desire of their families for considerable periods of time, often two to four years. It is important to recognize that the lines between a love-marriage 
and arranged marriage are not as distinct as they might have been a generation ago. While 'traditional' arranged marriages (where the bride and groom had not met prior to marriage) still occur throughout South Asia and the South Asian diaspora (Biao 2005;

Sheel 2005: 337) over the last few decades, it has become increasingly common for potential spouses to meet each other once or several times before they decide to pursue a marriage alliance. Though these types of arranged marriages are regarded as more liberal than 'traditional' ones, it is important to acknowledge that they still occur within constrained societal and gendered parameters.

With transnational marriage alliances occurring often (Biao 2005; Sheel 2005: 348), the lines become further blurred. As one woman, Farzana, explained, she was considerably older (in her late thirties) when she responded to her husband's newspaper advertisement seeking a bride. When her husband came to see her in India from Canada, she explained that it was 'sort-of arranged but not entirely', because it was only after a period of phone call exchanges and several meetings that they agreed to marriage. In her situation, the differences in their communities and castes, factors that usually play a significant role (Biao 2005) in determining 'traditional arranged marriages,' did not matter to either of them or their families at the time.

\section{Conclusion:}

The women interviewed for this study came from relatively diverse backgrounds in regards to age, caste, their class status in their country of origin, their education, regional affiliation and religions. Many of them had work experience and some education from their home countries and also from Canada. At the time of the interviews many of the women were living in poverty, and relied on government social assistance in order to 
maintain their households. The few women who were working were employed casually, part-time or in shift work, i.e., precarious employment situations.

Despite the diversity of the participants, all women in this study were primarily recruited from two of the main SAWOs in Toronto. Selecting participants from these two locations caused some limitations in terms of the scope of this study with regard to measuring the successes and shortcomings of these agencies. For example, this study is limited in that I was only able to access survivors who had used the services of the agencies, rather than women who continue to face wife abuse and do not receive help from SAWOs, because of socioeconomic and personal reasons. The following chapter examines how the women who did receive help from these SAWOs felt about the agencies' work and about other social services they have encountered. 


\section{Chapter 3: LIFE AFTER WIFE ABUSE}

While the previous chapters drew attention to the diversity of the participants and explored the academic literature in regards to SAWOs, as well as the cultural context and the socio-economic context of VAW, this chapter provides a brief overview of the types of abuse experienced by South Asian women in the Greater Toronto Area and articulates how women feel about such services from their own perspective.

The analysis of the data emerging from interviews with the 18 women participants identified four major thematic areas related to their life experiences: 1) gender roles and marriage, 2) the work of the SAWOs, 3) social welfare agencies such as shelters, legal aid and Ontario Works, and 4) current social situation. Each of these themes is addressed in the sections that follow.

\section{Types of Abuse:}

As a preface to this chapter, it is important to note that though I did not directly inquire about the types of abuse that the women faced, many times the women would disclose that information to me. In order to understand the challenges that these women faced and the types of services and/or support they required, it is important look at the nature of the abuse that these women endured.

All of the women experienced various types of emotional, sexual, financial and physical abuse. Some of the women dealt with their abusive partners for over 10 years, while some of the women experienced abuse for less than three years. All of the women experienced some kind of verbal abuse (a form of emotional abuse), where they were called 'stupid,' 'incompetent' and had profanities levelled at them. With the exception of 
three women, they experienced some kind of physical abuse as well. Sometimes their physical abuse was severe; some of the women's immediate family members were also subjected to physical assaults (this will be discussed in detail later). Where children were involved, only two women expressed that their children were also either physically or sexually abused by their spouses. One of the women, Usha, talked about how her husband often sexually abused her while making her watch 'blue movies', and instructing her to perform sexual acts against her will (Usha, March 1, 2006).

Two of the women mentioned that their husband and/or in-laws used technology to control and manipulate them. Pamela talked about how her living quarters were located in the basement when she and her husband lived with her in-laws. Within months of moving in with her husband and in-laws, her new family had installed multiple cameras in the basement to monitor her activities. Essentially, Pamela was not allowed to go out of the house (except for work), and her husband and in-laws controlled her movements through the camera system they installed. Pamela stated that it increasingly became a problem when her in-laws started to monitor the time when she would arrive from work and they reprimanded her if she was late. When they needed her to work for them, they could easily check if she was available.

Likewise, another woman, Alpana, talked about how her husband (a computerprogrammer) was able to check her emails and communications with her friends and family - by decoding her username and passwords for her email addresses and for her bank accounts. This way he was able to restrict her interactions with other people and also monitor her finances and exert financial abuse. The use of technology to exert control and abuse women is a new issue that has potential for future exploration. 
While abuse is not gender-specific and men can face abuse by their women partners as well, there are gender specific elements that can often exacerbate the conditions of wife-abuse. The next section examines how adherence to gender roles and how marriage and migration play a role in wife-abuse.

\section{PART 1: Gender Roles, Marriage and Migration}

Whether a couple lives in a joint-family (extended family) or in a nuclear family setting, it is a very common saying in India that 'marriage brings two families together', i.e., marriage is not just the union of two individuals but rather it is a relationship that is fostered between two families (the husband and wife's extended families) throughout their marriage. So on special holidays, birthdays, and religious occasions, gifts, money and greetings are always exchanged between families throughout one's lifetime. This lifelong connection between families has led to a preference for marriages that are arranged (or matched) along the lines of caste, class, regional affiliations, language and ethnic similarities.

While many studies focusing on South Asians and marriage tend to discuss dowry, the women participants for this study did not mention dowry as an issue related to their marriages. In fact, very few of the women mentioned dowry at all, and unlike most studies about South Asian women (Sheel 2005: 336), difficulties with dowry did not seem to play a huge part in this study, possibly as this element was not focused on. However, one of the women, Salima, mentioned that she found living in Canada more difficult because her husband's relatives in India demanded more dowry and gifts from her on a regular basis: 
To be honest, over here - I have had much more of a headache. For example - I had to continually give a lot of dowry and gifts over here. None of my other sisters had to ever do anything like this - and I have five sisters. There was a lot of festivals, Diwali, Rakhi and Lori $^{7}$ - I had to give a lot of gifts to his parents and the rest of his family on those occasions. I had to always give them something - if I didn't give something to someone or I missed someone, then it would cause a lot of fights. I think that's why so much fighting increased on our house. (Salima, May 11, 2006)

With increased trans-migrational marriages, dowry demands have become far more complicated and expectations for dowry seem to be higher for women who migrate to developed countries. The underlying assumption of many South Asians is that people who live overseas are better off (Sheel 2005: 345). From Salima's example, it would seem likely that her in-laws started to have higher material expectations of her because of her residence abroad.

In addition to the economic implications of trans-migrational marriages, cultural norms and values still play a large part in influencing gender roles. Most analyses of gender roles in South Asian cultures suggest that there is a heavy influence of Hindu mythology (Goel 2005: 656) and texts in the role of women in most South Asian countries - including the predominantly Islamic countries of Pakistan and Bangladesh. This can be explained by the influence of cultural norms of Hinduism (Kabeer 1999: 443) prior to the post-colonial separation of West and East Pakistan, respectively. The greatest difference between the Hindu and Muslim religions, with regard to marriage and gender roles, is that divorce is an acceptable act initiated by either the husband or the wife in Islam, while in Hinduism it is believed that marriages are eternal (Goel 2005: 649; Rahim 2000: 197). Despite divorce being acceptable in the religion of Islam, it is largely culturally frowned upon in South Asian countries, and women are assumed to need a

\footnotetext{
${ }^{7}$ Names of different South Asian Hindu festivals in which gifts are exchanged among family members.
} 
male to take care of them if they leave their husbands (Rahim 2000: 190). Therefore, if a woman leaves her husband, it becomes the responsibility of the woman's male family members to take her in and provide for her. Gender role ideals in South Asian cultures for women entail a great deal of 'traditional' femininity; women in all South Asian cultures are valued for being giving, nurturing, caring and respectful to the needs of others in their family rather than their own (Goel 2005: 640; Subrahmanyan 1999). As Goel puts it, women are encouraged to "self-sacrifice rather than self-preserve" (Goel 2005: 640). In addition to the ideal of self-sacrifice, marriage is seen as an essential milestone in an adult's life, and gender roles for women are ultimately tied to their marital status.

Women in most South Asian cultures are largely expected to be the preservers of culture. In diasporic communities this concept is enhanced even further as women must adhere to an 'imagined South Asian femininity' as well, one that is in contrast to 'immoral Canadian standards' (Sheel 2005: 349). Most of the women interviewed were aware of the importance of being married in order to attain favourable social status in the community. As Asha explains:

My mom was very confident and she was very different. She was a rebel. She got by easy [sic] because she was married, and married women can get away with murder. In [her country of origin] women's reputations are tied to their marital status. (Asha, February 27, 2006)

In comparison, Meena and Asha, both of whom left their countries after they separated from their husbands, felt it was easier to live in Canada as a single woman:

I didn't want to remarry - and it's not nice back home to stay single. It's nice here. Everywhere women are in a complicated situation or some problem, but I think Canada is a little bit accommodating situation. I prefer Canada because I don't want to marry. It is easier to be single here. (Meena, January 17, 2007) 
Though most of the women responded that they felt life was easier as a single woman in Canada, when asked about whether life was better for women in Canada or back home in relation to their marriages, the survivors mostly answered 'back home.' The responses of the women varied according to how long they had moved to Canada after their marriage. The women who had married and then immediately migrated largely presumed that married life 'back home' was better and some confessed to not knowing as they had spent most of their married life in Canada. However, the few women that had experienced married life in their country of origin had a mixed response, and some of them such as Meena found married life to be much more difficult in their country of origin:

It is harder back home. Here women have a lot of freedom and financial freedom here. Back home there are lot of barriers. There is no financial and social freedom. Back home I had a lot of financial freedom - but no social freedom, so it was a tough situation for me back home. (Meena, January 17, 2007)

However, Meena also added that certain aspects of living in her country of origin were better because of the support of her family:

Back home is better. If you have skills, family and job here - then it might be easier. You need family - maybe just one or two blood-relatives, not necessarily your mother and father. As long as you have a good relation here you will be okay. If you have nobody here then it is very difficult - not just women, but men too. (Meena, January 17, 2007)

This sentiment is echoed throughout the responses among the women and, as we will see later, isolation and the lack of a social network are among the main challenges that women who leave abusive relationships face. From the women's responses it was clear that while social restrictions on gender roles were more rigidly enforced in South Asian countries, women 'back home' had assistance from their family to help them through 
times of crisis, especially when women experienced marital problems. As Farzana explains:

Yes, of course - if my husband had initiated this nonsense with me there, my family would have made sure that next time he doesn't repeat it.

(Farzana, February 22, 2006).

Family plays an important part in women's escape from abuse. Most of the survivors felt that if they had had relatives or close family members here, their marital problems would not be as difficult, because their family members might have intervened in the situation. One of the survivors, Rita, explained about how she managed to survive her abuse and got help from her brother after he migrated to Canada:

No, my brother wasn't here - when I was in the hospital then he came [to Canada]. I was almost dying - so that's why he came. I got this second life because my brother was here. I could have gone [died]. (Rita, May 22, 2006)

All of the women in this study felt very isolated, lonely and separated from their family, friends and community. In recent years, researchers have started to recognize that isolation is, in fact, a method of abuse in and of itself (Abraham 2000:221), and that a large part of an abuser's means of exerting control over a woman is by isolating her from her family and friends (Abraham 2000: 221; Bancroft 2002: 74). Making sure that a woman slowly loses contact with her friends and family enables an abuser to ensure that the abused does not seek or get support from family and friends who may encourage her to leave her abusive relationship. Margaret Abraham, a researcher who has written many articles on wife abuse in the South Asian community, posits that isolation occurs at three different levels: 1) emotional isolation in the marital relationship itself; 2) interaction with informal networks including family and friends; and, 3) accessibility and availability of formal institutions such as community organizations, and the political and legal 
systems in a new setting (Abraham 2000:222). These were also frequent themes that came up in the interviews. As well, for many South Asian men, isolation as a form of abuse is very easy to exert as their wives often arrive in Canada dependent on their husband's sponsorship. Therefore, South Asian women are already limited in their social networks upon arrival, and the limited networks they may have may be their husbands' connections or those of his family.

Like many immigrants, most of the survivors interviewed did not have large social networks or family members in Canada. Many times, a husband actually had relatives and/or friends in Canada prior to his marriage to a woman from South Asia, especially in the cases of transnational marriages (Palriwala and Uberoi 2005: x). The fact that most of the women who moved here were dependent on their husband's sponsorship put them in a precarious position, as Shirwadkar (2004: 864) notes:

An Indian immigrant woman usually comes to Canada [is] totally dependent on a spouse and, in most cases, unaware of immigration laws. Her usual close-knit kin and extended family network, and her neighbourhood support and community resources, are suddenly lost or substantially reduced. (Shirwadkar 2004: 864)

Having family in Canada did, in fact, increase the help that women received from their family members after separation from their husbands, as was the case with Salima, Rita, Veena and Nancy in terms of getting emotional support, temporary housing, information and some funds. Salima, whose sister sponsored her, initially lived with her sister for several years after separating from her husband. Likewise, Nancy also stayed with her brother's family for the first few months after her separation.

Though it is not within the scope of this research, it is important to acknowledge that when facing marital difficulties, women face many challenges in requesting that an 
extended family member come to visit them from overseas, due to Canada's complicated immigration and visa system. Likewise, it is also very challenging for women to go and visit their family members abroad, especially if they are receiving social assistance. These types of restrictions on travel further impede women from accessing the kind of family support that they need while living with or separating from an abusive spouse.

Loneliness was also a common thread in interviews with nearly all of the women survivors. As this was a very prevalent theme, it is examined further in other parts of this chapter. The culmination of various factors limited how often women were able to interact with one another, other friends and family members. Having to live in the suburbs, where most women do not have access to cars and most community resources are farther away (such as temples, mosques, churches and community centres), was one factor that contributed to women's isolation and loneliness. Other factors included having few (or no) family members in Canada, little opportunity for employment, the responsibility of young children, and having very little (if any) disposable income of their own.

For the few women who did have family members in Canada, such as Salima, it was difficult for them to meet up as these family members had their own family commitments, lived far away and worked long hours. As Salima explains:

I feel lonely without my family sometimes - my brother works for 16 hours [a day] - so it was hard at first. My sister also works a lot - additionally, they don't come to my house, I usually go to their houses. Sometimes I feel lonely because of them. (Salima, May 11, 2006)

The fact that many of these women's family members originally migrated to Canada before the women did, hence, the women felt other family members were far more settled and established, was also a difference that several women commented on. Though 
women may find new networks and friends within the same community, the established status of other family members, other South Asians and community members makes it difficult to really connect with these people. Kruti explains:

Yes, but the thing is that this is a different system, right - than my country. So when my people came 5 years, 6 years, 10 years before I came - they are already used to this lifestyle - I am not blending with the system. But they have busy-ness in their everyday life. New immigrants don't have that much busy-ness, I mean. They are looking for jobs - but they need to use their time - for social, to work and earning. But at that time they can't use their time properly and for emotional reasons that I told - their feelings of vulnerability - they need lots of support despite the fact that they found some community friends. They are too busy. (Kruti, May 20, 2006)

As the data from interviews with the women in this study suggest, gender roles in South Asian cultures are largely influenced by patriarchal and Hindu norms. Marriage is considered a very important milestone in an adult's life and divorce is frowned upon. In recent decades, trans-migrational marriages have become common, and with transmigration women face new challenges especially with regard to maintaining traditional kinship networks. Without the support of their family and their community, women feel isolated and have very few outlets to talk to anyone about their marital problems. Women's loneliness stems, in part, from their location in suburbs and the lack of transport, their distance from supportive services and community resources and members, as well as the lack of familial support.

In order to counter their feelings of isolation, some women's secondary reason for using the services of the South Asian Women's Organizations (SAWOs) was in the hopes of connecting with other women, to make friends and seek mutual support. Even in this study, at least four women wanted to be interviewed together. Veena and Nancy became close friends initially through their social worker, and then by coincidence again through 
the SAWO. As they lived in the same housing complex, they were able to visit each other every day for company. Likewise, some of the women befriended their interpreters and job counselors as well. Therefore in addition to their direct primary services and assistance programs, the SAWOs also helped foster relationships and community amongst wife abuse survivors.

\section{PART 2: Work of the South Asian Women's Organizations (SAWOs):}

When a woman experiences abuse, she either seeks out help from the SAWO directly or is referred to the agency via another community service organization. The women in this study found out about the SAWOs from various sources, including other aid workers, doctors, family, friends, babysitters and other survivors of wife abuse. After visiting the agency, the agency served as a portal for the woman's needs and assisted her in the various facets of her life, based on her finances and personal requirements, including offering other types of support services:

We offer different kinds of services like life-settlement services for newcomers, language instruction for newcomers, computer training, job search workshops, senior support groups, women's wellness support groups, women's program, youth program, mental health support groups. (Megha, February 8, 2006)

Every one of the participants in this study had used at least one or more of these services at one, two or all three of the SAWOs that I visited. The study participants used a wide variety of services, such as: individual and group counselling; job search and resume writing workshops; English as a Second Language (ESL) courses; empowerment workshops; assistance in finding shelter and housing; social assistance; legal aid; and access to free clothing and furniture supplied by the SAWOs and affiliated programs. 
In addition to their direct work with abused women, the counselors and other staff of the SAWOs also collaborate on community building projects, and work with other agencies that serve women and immigrants. Megha, an experienced counselor, elaborated:

We do fundraising, we do outreach, we sit on different committees, like the [name of coalition], Children's Aid and VAW [Violence Against Women] committees. So there are different committees that we sit on. We do advocacy. We do transitional support work, different kinds of things. (Megha, February 8, 2006)

Though the agencies service women from other ethnic communities, most of the survivors agreed that having a counselor from a similar ethnic/racial background was helpful, while only two of them felt that it was not necessary, and felt that they may have received similar help from counselors of other ethnic backgrounds. It is important to note that, unlike the other women, these two women were of upper-middle class status before they left their countries of origin and were very fluent in English. Others, however, felt that it was imperative that the counselor was from the same background, as one survivor explained:

Yes, I have another counselor, therapist at a hospital. And she's of [a European] background. And there is a lot of things that I will not tell her - that I would tell [counselor of South Asian background] - because of the culture difference. But mind you - she is very much like us, she's very spiritual also. So I am still able to communicate with her - but with [South Asian counselor] she understands the Caribbean way ${ }^{8}$ and she's Hindu, so when we hear a bhajan [devotional song] you know... so there is more of a connection on this side than on that side. (Sidra, February 20, 2006)

Along with the counselors' familiarity with culture and language, others pointed out that the SAWOs provided an opportunity to meet other women and to feel like they belonged, as explained by Kruti (a survivor and service-provider):

\footnotetext{
${ }^{8}$ Her counselor was not from the West Indies like her, but was still understanding of her background because she was also of South Asian descent and a Hindu like her.
} 
They have a very good understanding of the cultural and sub-cultural thing. They pay attention and I really like that. Maybe if the lady is from Afghan or Iran or Bengali - it doesn't matter - but the good counselor they develop the relationship in such a way that not everything is cultural or whatever it is. They use a combination. They try to do something if they feel assimilated or if they feel out of place. So if there is a group session they not only have an interpreter but they have lots of support in group discussion also. They try to find someone who is an interpreter and who can explain to them in an ethnic cultural way. I like that a lot. Even if they have a special event - they do it in a very integrated way. They organize it in that part. (Kruti, May 20, 2006)

The majority of the women had experienced wife abuse in Canada, however, the few women who had experienced wife abuse in their country of origin also used the SAWOs for various reasons. For example, Asha used counseling services, job training and assertiveness training classes at both of the agencies. Likewise, Meena also used the job and resume writing services at one of the agencies. It is evident from this study that the SAWOs played a pivotal role in many of the women's lives regarding their transition from living in an abusive situation to living independently. While the services of the SAWO are often time-limited and often used only for a brief period of time by most women, for some of the women they serve as an important hub of resources, of which the most important service is most often the individual counselling services.

\section{Counselling:}

All of the women expressed gratitude towards the work of the SAWOs, and especially towards the individual counselors and the one-on-one counselling services:

Yeah, normally when I call - she [the counselor] talks to me. She's very, very nice. You know when somebody does something for me - I never forget that person, and Megha she is a godsend for me. This life, I am seeing [it] because of her. Otherwise - it's not for me only; I also saved my child as well. If I had gone what would happen to my life? So, she didn't save one life - she saved so many lives. If I am gone, my mother and family they could have been - you know...(Rita, May 22, 2006) 
They actually try to help another person; abused women are in a very vulnerable situation so they try to really help them. They often give them support and services when they are in a vulnerable situation. And they helped me try to find a job also. When I met them with my friend's problem - because her family situation is a really bad problem. (Meena, January 17, 2007)

Many of the women had undergone a variety of therapeutic treatments including psychiatric treatment, and they found that, unlike psychiatry, counselling was a place where they could be themselves.

From my experience, my psychiatrist will sit and he will just write everything you say. And he'll just write, write, write, write... And at the end of it - you tell him how you feel and if you took the medication. And if he feels that he needs to change the medication he will - and he'll give you a new prescription, "Okay, we'll see you in three weeks then." Whereas with the counselling session, we're both speaking to each other - I'm telling her everything and she's not writing. She's not writing anything. She is telling me and I am telling her. She tells me you can do this, you can do this, how can you change those things. You have a reason to live; you know you have two kids. That's what I need, I need a boost, I don't need some guy sitting at a table, just writing everything I say. And he's a psychiatrist, which I guess is fine, but a psychologist probably does more speaking. (Sidra, February 20, 2006)

There were very few shortcomings expressed by the survivors of wife abuse when it came to the work of the SAWOs. The only consistent problem that women had was that counselling did not last long enough. Though individual counselors attempted to assist by continuing counselling at many of the women's requests even three years after they left their husbands, it was not always feasible because of their heavy workloads. The counselors themselves acknowledged that the time they are allotted to work on one case is not sufficient for women, as each woman's case is different.

Some women also expressed that they did not receive as much information as they would have liked, but these instances were rare. As Pamela explained: 
I'm happy with their help. I wasn't sure about the process. They helped me with my crisis. But sometimes I wish I could know more about situations, and have knowledge about them (i.e., legal processes, etc.). For example how things work regarding legal aid, lawyer, before I leave the home or the shelter. I want to know more about the law and my rights. Because I am new I don't have any other contacts. I wish I had known all these things. I could have taken more steps. (Pamela, February 13, 2006)

Pamela felt that she was not given enough information about the process of separation prior to leaving her husband. She explained that, as a newcomer to the country, she did not know enough about her rights and the law.

The only other consistent problem that many of the women pointed out had to do with the group counselling sessions that were increasingly becoming a part of the work of the SAWOs. One woman talked about the clashing cultural and social values that arose between the women at group counselling sessions, and how gossip arose about the personal lives of other clients of the agency during such sessions:

No, I don't like it. The ladies are sitting, talking stupid nonsense, like village philosophy, like no, no, no - as long as your husband is beating you - it's fine, not liking the beating you are not good. They were teasing Mary [another survivor] that day, I don't know - Mary had found a boyfriend or something that day - and then we were talking and this old lady was interrupting saying, "What's the big deal with you - you caught someone else anyways." That's not the right comment to make for anyone, maybe she's found her life much better, I would rather avoid this stuff. I would rather come home, watch TV and enjoy. (Farzana, February 22, 2006)

Others, like Asha, talked about how group counselling did not establish long-term objectives for individual women, and that group counselling needed to be modified so that women received emotional support, and had an opportunity to network in a more casual environment, such as a woman's club, rather than a formal group setting that only focused on abuse: 
All we did was sit around and chat. I was not impressed with it. I didn't feel that most of the women there were educated, they were mostly uneducated. I had no rapport with them. There were no other activities to involve us in [aside from the discussion about abuse]. We do need emotional support, but maybe at an Asian women's club or organization where women can enjoy company emotionally. Women need to cooperate with each other. (Asha, February 27, 2006)

Only one woman found that the group counselling allowed her to network with other women, and provided an opportunity for social engagement. She particularly appreciated that the agency offered childcare facilities during group counselling sessions.

The counselors themselves acknowledged that group counselling was problematic due to confidentiality concerns, given that women might know each other beyond the confines of the group:

Because confidentiality is a huge piece, because they can get into more harm with the group setting. It's a small community - it's close knit and they meet outside. (Megha, February 8, 2006)

Though the counselors felt that group counselling was not an effective way of counselling, they were forced to add group counselling on to the roster of their services to fulfill the government's requirements. Group counselling helped to reduce the number of individual client sessions by streamlining their services and helping women in greater numbers.

It is evident from this study that most wife abuse survivors agreed that they needed to interact with women who had similar experiences. However, many of them felt that the environment of a SAWO was not conducive to facilitating the kind of interaction that they needed from other women. These women were diversified in terms of age and social values, and the SAWOs' group sessions forced women who lived close to one another, but who did not necessarily like each other, to interact with one another. The 
women's sharing of intimate experiences during these sessions created an environment that fostered gossip, which proved to be problematic for the women involved. While individual counselling sessions were considered valuable, financial and bureaucratic constraints filtered women into group sessions that were less useful.

\section{Counselors' Experiences:}

All three counselors had post-graduate training. In addition to the three counselors, two women in this study were wife-abuse support workers who were also wife abuse survivors with post-graduate training. All of the counselors and support workers spoke multiple languages. These were useful skills because they allowed them to directly counsel women in a language that was more familiar and comfortable to them.

The workload of the counsellors was demanding, and all three of them expressed concerns about burnout, and had little time for debriefing. Many times the counselors proceed to help women outside of work hours, because of the demands for assistance, and because they recognize the urgency of their work. In fact, they said that they had to underreport the number of women they helped. One of the counselors said she easily saw over 500 clients a year. The recommended number of people she can report to the government is supposed to be fewer than 200 clients. Another counselor said she saw about 300 clients a year and received at least 30 calls a day for assistance of some sort.

In addition to their heavy workload, the work of the counselors often affected their personal lives. In extreme situations, all of the counselors had also experienced death threats from ex-husbands of the women whom they counselled. A married counselor told me that her counselling work affected her relationship with her husband, too, because many of her clients were beautiful and educated, and that if spousal affairs 
could happen to them, then she believed it could happen to her too. Effectively, her work as a counselor made her feel insecure in her own marital relationship.

In addition to being overworked, the counselors also discussed the systemic challenges that impacted the success of their work because of the lack of support they received from other institutions and the public. They felt that there was disbelief amongst other affiliated professionals such as lawyers, police, judges, health professionals and even other members of their own agencies in regards to the sincerity of the women they counselled. They would often get confronted about the legitimacy of their cases and whether or not many of their clients weren't just 'taking advantage of the system.' Thus, the counselors ended up working overtime year long, but very little of their work was taken seriously by other professionals who played a key role in providing security and justice for the survivors of wife abuse. As Shilpa, a counselor, stated:

I have people in my own community who turn around and say: "Shilpa, I mean come on, don't you ever think that some of these women are exaggerating? You believe everybody?" My only response is that I can't play God and I can't play judge. I am a crisis intervention worker. I am there to counsel, to facilitate support groups and to do primary crises intervention. The police are there to arrest or report abuse. I am there to counsel and do crises. And the judge is to judge. If every client that comes to me and tells me a story am I supposed to sit and dissect and dissect the story and decide that I don't believe her story - so I am not going to help her - that is not my job. (Shilpa, February 16, 2006)

All three of the counselors also expressed dismay with the lack of advancements and improvements in the state of their field as well. As Shilpa explained:

But the thing is that this field is losing good people because they are burning out. I am sure that there are others like me. I don't even have time to do networking with these counselors. That's why when people from university contact me - and I say don't tape me or anything I always wonder where is all this research going? (Shilpa, February 16, 2006)

And later: 
We go to all these meetings, we talk about all these things, define wife-abuse, redefine wife-abuse. Come on! We all knows what wife abuse is. It's gone beyond solutions, we have to be solution oriented - we are even running out of solutions. Because the solutions are there if you have the rest of the system working by itself [speaker's emphasis]. We have had so many conferences; we have finally redefined wife assault. And we have agreed that it encompasses emotional, financial, mental, psychological, neglect and our women still have to go around and start stripping to convince people to show bruises. Men have become very smart - that's what it's all about...

There has to be other ways of doing something. The system, even this power program that we have - you know the partner abuse response program - we are saying that at least we have something - something's better than nothing. How many years are we going to go on believing something is better than nothing [speaker's emphasis]? (Shilpa, February 16, 2006)

In sum, the work of the SAWOs plays a large part in the healing process of wife abuse survivors' lives. More than just providing counselling, SAWOs serve as a hub for information, resources and social gatherings. Many women appreciate the cultural and linguistic familiarity that the counselors have with them. The only major challenge women experienced with the SAWOs was interacting with other SAWO clients because of the interpersonal differences that presented themselves in their interactions during group counselling sessions, and their interactions in the South Asian community at large. While counselors have a high level of job satisfaction, all of them talked about stress and being over-worked. Their interactions with other service organizations such as social assistance, housing and legal aid played a large part in some of their feelings of being overwhelmed. 


\section{PART 3: Welfare, Employment, Housing, and Legal Aid - Women Living Under}

\section{$\underline{\text { Neoliberalism }}$}

As briefly explained in the introductory chapter, economic policies since the mid1970 's to 80 's have resulted in an increase in the dismantling of the welfare state by implementing neoliberal policies globally, or policies that focus on deregulation and increasing privatization. These policies not only have a political or policy angle but a guiding philosophy whereby there is a strong focus on an individual's potential ability or 'responsibility' rather than collective social safety nets or 'collective rights' (Evans 2007: 31; Morrow, Hankivsky and Varcoe 2004: 358). When neoliberal philosophies play out in terms of public policy, it is the dismantling of the welfare state and the will of private markets that gets favoured over public and government run programs.

During the course of this research, Ontario works, legal aid and social services agencies were repeatedly brought into the discussion by the participants, therefore, it seems imperative to discuss the changes that have taken place at the macro, policy level.

\section{Ontario Works and Work Opportunities:}

Some of the women talked about their immigration experiences at length and how in South Asian countries there is a glamourized view of a 'Western lifestyle.' It is largely assumed that people living in West have accumulated significant wealth and therefore must live comfortable lives. As Merchant has explained, "Many South Asian families come to the United States [and Canada], a land of hopes and dreams, with great expectations" (Merchant 2000: 251). However, upon arrival in Canada the reality for most of these women does not match up to what they heard about Canada prior to moving 
here, and most of them live in conditions of poverty. As Yasmin Jiwani discusses in Discourses of Denial, "immigrants go through three distinct stages during the process of resettlement in Canada: euphoria, disillusionment, and adaptation. These periods accentuate the stresses of migration that mark the lives of all immigrants, resulting in a sense of loss, helplessness, and alienation..." (Jiwani 2006: 148-9).

Similarly, one of the participants in this study, Salima sums up common assumptions about Canada, and what her relatives and friends thought that her life was like over here:

Country is very pretty, but like people in India say that Canada was the best - that there are lots of facilities - and food, etc. Because I am from Delhi [India's metropolitan capital] - I didn't see anything special about Canada. Everyone in India always assumed that everyone here is making loads of money - and we are all making tons of money. Basically, if you are rich and if you have money, then you can get anything you want; it doesn't matter where you are - you can have the same things here and you can have the same things there. (Salima, May 11, 2006)

For Salima and many of the other women in the study, it is very difficult to find a suitable occupation to make ends meet. For many of them, social assistance payments do not cover all their expenses, and payments are often cut off when problems arise. For example, in Salima's case, she was receiving child support and alimony from her husband, however, after receiving payments from him for six months, he suddenly stopped. Consequently, because she was supposed to be receiving payments from her husband, her social assistance was cut off. She was forced to look for work, through Ontario Works, which created further financial problems such as being able to purchase adequate food, children's clothing and even paying market rent. Salima explains her difficulty in finding a job: 
I am looking for work - but I am not getting the kind of work I am looking for - I have tried to find some kind of factory job or anything like that - and it's been too difficult to find anything. (Salima, May 11, 2006)

Being one of the least educated women in this study (she had a high school diploma), Salima's dilemma is not unique. At least six of the women interviewed had some level of post-graduate education, in a variety of fields. Though some of these women were working, their employment was not in their field of study nor were they being compensated well, often working in precarious employment situations. Asha, who was working a part-time administrative job and also working as a self-employed saleswoman selling beauty products from her home, elaborated on her situation with significant insight:

There are also money problems over here for sure. People always ask me how do you survive as a single woman here. It's harder to earn money here. Immigration is a scam [speaker's emphasis]. Educated workers basically work in factories. Volunteer work also scams your labour. Educated labour has respect but you are working for $\$ 8-9 /$ hour. If you are white you make more. (Asha, February 27 , 2006)

Like Asha, most of the women who had worked in Canada or are still working, worked in fairly low-paid occupations such as sales clerks and factory workers. As other research suggests, women who worked in positions other than clerical or in factories, often held positions that were part-time, were on a contract basis, required oddly timed shift work, did not offer permanence or stability, and had no benefits (Evans 2007: 30; Teelucksingh and Gallabuzi 2005: 4).

Asha, who had experienced abuse in her country of origin, used one of the SAWOs resumé workshops to help her improve her job prospects. Though SAWOs do 
not necessarily provide job placements, there are expectations that undergoing training would assist in finding meaningful work. Asha was critical of her experience:

I have also taken job training with [name of social service agency]. I used the building resume service. I was not very impressed with their services. They try to get you to network, but they don't get you a job. You have to have Canadian experience either way. The only benefit is that you just don't rot at home and sit around getting depressed. It's basically created to keep you mentally alive. Immigration is a whole big scam. (Asha, February 27, 2006)

Overwhelmingly, from this study it was obvious that the kinds of policies enacted by Ontario Works often places women in a bind. If women are able to work, they are often forced to get back to work immediately after their separation. The pressure can be overwhelming and does not accommodate other aspects of women's lives, such as the fact that many of these women are still struggling with divorce proceedings, childcare, relocation, mental health and other health problems.

Pamela, another study participant, explained her predicament with Ontario Works and their 'work-fare legislation':

I have been trying to tell the Ontario Works social worker that it hasn't even been two years since my separation. My son is having so many health problems. In five-six months he'll finally be in school full-time, that's all the time I need and then I can go to work. The divorce case has been filed. How am I supposed to work, go through divorce proceedings and be at home for my son? My divorce case is still pending. I have cried over the phone to my social worker to get me some more time for work, but she says simply that she has hundreds of clients and that it's impossible to help every single one like this. (Pamela, February 13, 2006)

More tellingly, Pamela even compares the bind she is in due to Ontario Works as a type of abuse:

I feel like their [Ontario Works] misunderstanding of my situation is abuse [speaker's emphasis]. (Pamela, February 13, 2006) 
Housing and Ontario Works are very interconnected in the lives of survivors. Often not having access to adequate housing or subsidized housing can create another cycle of poverty for survivors of domestic violence. As Sidra explains:

Okay, right now I am going to give you figures so that you can get an idea - can I give you figures? I get $\$ 670$ a month for both kids, child support. I get Ontario Works $\$ 449$, and the government gives me $\$ 169$. So that adds up to $\$ 670+\$ 449$, which is 11 or 12 something and I pay $\$ 950$ rent for this apartment. And I have to pay $\$ 125$ for daycare, even though it's subsidized I still have to pay a little. (Sidra, February 20, 2006)

Based on Sidra's calculations, it's hard to imagine what kind of nourishment she is able to provide for herself and her family. She explains:

[A counselor from the agency] takes me to the food bank, and it's the best thing, and I can't say anything about the food bank. But there are still things that you don't get in the food bank that your kids still want. You don't get yogurt in the food bank. You don't get, you know, popsicles for them. So, with the money that I have whatever little bills I have to pay, it's gone in bills and that's it. I find that there is no totally, no, you know what I'm hoping that [counselor's] work comes through and she finds me supportive housing. And I am really hoping that I come through and that I can do it here. It's very, very hard. But because I have a depression, like if you have a disability you get it faster, as opposed to somebody who is just waiting. (Sidra February 20, 2006)

From Sidra's example we can see that finding subsidized, safe and adequate housing becomes an imperative in order to alleviate the burden of having to pay market rent on Ontario Works payments.

Women who receive ODSP (Ontario Disability Support Program) payments over Ontario Works payments are in a similar, but slightly different, bind. While they receive slightly higher payments than women who receive Ontario Works money, they must account for all expenses (medical and other) in great detail. Often specialized items that are not deemed essential by support workers are not approved, as Nancy explains: 
Financially we live, but we live in such dire situations and with such difficulties. It's hard to make ends meet. Because we have to come and go. For example if I have to go somewhere - I will call the ODSP people, then I call the welfare people - because they say that we don't give you welfare. I tell them that look I have high diabetes and blood sugar levels - I need \$200-300 shoes to walk in. But the ODSP people say we don't take care of those things. And in that time - I have to leave it be. What can I do? (Nancy, February 21, 2006)

Like Sidra's Ontario Works payments, Nancy finds it very difficult to make ends meet on ODSP:

I can't pay the phone bills, eat and pay the rent in \$300. ODSP is about $\$ 595-$ it costs $\$ 200$ for car insurance a month. $\$ 169$ is my rent, and $\$ 30$ for parking. How can I eat, I also have to put petrol in my car. If I don't go to my doctor's appointments - I don't get paid. They think that if I don't go to the doctor's that must mean I'm fine, but they don't realize that to go to my doctor's appointments it costs money. Basically, sometimes they give me money - sometimes they don't. Sometimes they give me $\$ 42$. They basically start and stop the welfare whenever. It's hard to get by like this - I have to live by beating myself up all the time. (Nancy, February 21, 2006)

From workfare case studies in the United States (Canadian data is not available),

researchers have found that women who have experienced wife abuse are more likely to be "welfare cyclers" who are less likely to maintain stability of employment over time (Tolman and Rosen 2001:153). This is because of the high rates of mental and physical health problems that survivors experience and that go unresolved, in addition to the material deprivation they face in making ends meet in low-paying employment. Despite the challenges survivors' experience, they often do seek employment, but with the state of precarious employment and the inaccessible system of childcare, welfare cycling is often an easier and more cost-effective solution to 'getting by' than working for minimum wage (Evans 2007: 36).

\footnotetext{
${ }^{9}$ Welfare cycling is a situation where an individual or family continually switches between periods of precarious employment and social assistance. I.e. when the precarious employment ends, they are back on social assistance and so forth.
} 
All of the counselors, too, understood the predicament and bind that workfare and legal aid policies place on women. Megha, a counselor, summarizes this:

They [Ontario Works] are re-victimizing the client and that's not fair. And you can't fight. Some women - have accumulated $\$ 2000, \$ 4000$, or $\$ 10,000$ - it doesn't matter how much money they have accumulated [before they went on Ontario Works]. They have accumulated it by sacrificing everything in their lives. They didn't have the best of life but when they are in a difficult situation they would want to get rid of that money too because they wouldn't be able to get help. And when they get rid of this money - they are seen as criminals. Why did you send money back home? Why did you do this? Instead of asking her - is there anything we can help you to do to help you to survive here? They want to know where did you send that money. She doesn't have a million dollars, she will never be able to buy a home. She can never have a decent education for her children because she is a single mother and she has to carry the burden of her children all the time. She has to take care of so many other needs. But still she is looked at as a suspect, and that is what is very bad for them. It's a great system but there are so many loopholes. (Megha, February 8, 2006)

Since the possibility of acquiring fulfilling and well-paying work seems so out of reach for South Asian wife abuse survivors and because there is a lack of recognition of their foreign education and training, many of these women believe that the only possibility for them to get out of the welfare cycle is to pursue further education. Many of the women talked about gaining further education to help their careers, but again due to their financial situation and because of their childcare responsibilities, they did not feel that such opportunities would be realized.

I think that I need to go back to school and find a career that will allow me more job opportunities. This is the only way women like us can survive with decent money. (Alpana, February 20, 2006)

I would like to read. Learn music. French improvement. Take more computer courses, I took one but now I've forgotten. I want to form a club for single women to help them improve their lives. I know many anti-depression strategies. Don't cry, you're not going to get everything in your life. Women need to study. We need to expand out of our communities. (Asha, February 27, 2006) 
Due to the constraints of work-fare policy, it has become much harder for women to gain training grants, subsidies and apprenticeship opportunities (Evans 2007: 36), thus making it financially even more difficult for women to pursue Canadian education and find adequate housing.

\section{Housing and Shelters:}

Prior to finding long-term housing, women who need to leave their abusive situations immediately must leave their homes and live in a shelter for a period of time. Although shelters are conceived as places of security for women who are trying to escape their abusive relationships, South Asian survivors of wife abuse largely seem to dislike the idea of shelters for a range of reasons (Sahota 2006). Three of the women who were Hindu-vegetarians complained about the lack of facilities for a vegetarian diet. They would have a very difficult time preparing their food in a way that they wanted. For many vegetarians, it is very difficult to eat food they know has been prepared with utensils or pots that are also used for meat preparations. Veena said she was lucky that in the shelter they allowed her to cook for her and her children because if you were a vegetarian woman on your own (without children) you had to eat whatever "flavorless pastawasta $^{10 \text { " was available (Veena, February } 21,2006) .}$

Several other women were also opposed to shelters. As one woman explained, she was very frustrated with the shelter system, and as a result she would 'escape' to her apartment as often as she could. Sometimes she would leave at night, other times in the day. She expressed a general sense of being denigrated by the shelter system, and she

\footnotetext{
10 "Wasta" - repeating the same word with a different sound in Hindi is used to diminish the original word's meaning. In this case the participant mentions it to indicate that pasta is not a substantial meal - but rather just a substitute for a home cooked meal that would require more time or labour to make.
} 
raised some important questions about why it was that she was expected to leave her home when she did not do anything wrong:

Shelters - have a designation of something, like a slum type of thing. I wasn't staying in the shelter because I couldn't take the pain from other women, their horrible stories were even worse than me. My question is that why do I have to leave, when I have a nice condominium - why do I have to live in a shelter? I was angry with my counselor - why aren't you building some safety and security within my house. And I didn't appreciate her at all for the shelter thing. (Chandrika, May 17, 2006)

As Chandrika rightfully asks, why do women who play a great part in building their homes, have to leave them? The inequity and lack of recognition of women's paid and unpaid contributions to the household were repeatedly highlighted in the interviews. In the case of Chandrika, she earned more than her husband, and, though they lived together, a large financial contribution to the home was hers. Very few women in this study approved of their shelter experience, as documented in literature as well (Koyama 2006), and what emerges from their interviews is a complex relationship between their feelings of rightful entitlement to their own homes and the personal and material challenges that come from living in temporary housing, where they must remain for, in many cases, upwards of a year.

Chandrika also added the following about her shelter experiences:

I was expecting her [the counselor] to go a little further to find out any other options to make sure that I am safe at my home, it is not mandatory to go to the shelter - it was not. Now I know that if she was putting a restraining order right away, then he [her husband] couldn't have done anything. She could have suggested me to put a lock on the inside so he couldn't break the door. She could help me get a private investigator or spy. She didn't do those things, and there should be more police force to find out what she didn't do. So that's why I didn't attend - the shelter is just like a hostel in my experience. But somehow it is always stressful - there is nothing to do. There is a weekly PNA [personal needs allowance], and food is on the table and always there is freedom, you go and do whatever it is that you are doing. The environment is always stressful - because there is a high volume of women. So extreme stress comes into the air, for me - it 
was difficult - because my daughter was never sleeping between 12am - 5am, because she was continuously crying. That time I had to sit down in a living room or the laundry room because - the whole residence was sleeping. They give you everything - but it is stressful, I don't know where that stress comes from - but it is there, it is even more depressing. (Chandrika, May 17, 2006)

Many women expressed the problems they had with shelters. In this regard, there was a difference between the types of responses that the counselors gave regarding the shelter system and the women themselves. While the counselors were often concerned with women finding a shelter and getting them out of an abusive situation, women themselves were more interested in finding ways through which they could maintain their homes and lifestyles, and not have to experience the kinds of inconveniences and discomfort that is brought about by the shelter experience.

During the course of a woman's stay at a shelter, finding more permanent, suitable, safe and affordable housing is a critical aspect of alleviating a large part of women's daily stress. As mentioned earlier, most of the women interviewed lived in the suburbs of Toronto in social housing, where most of the larger (and cheaper) stores, schools, community centres, religious organizations, hospitals, doctors and other services are far away ${ }^{11}$. There are two parallel phenomena that contribute to South Asian survivors of wife abuse living in areas that have few resources. Firstly, most municipal governments in metropolitan cities have increasingly adopted neoliberal policies globally, including Toronto, in regards to housing (Davidson 2007: 492; Slater 2004: 322).

Secondly, new immigrants, working class and social housing projects are being shifted to deprived $^{12}$ suburban centres throughout Canada (Ley and Smith 2000).

\footnotetext{
${ }^{11}$ Without access to a car, I would not have been able to get to most of these places.

${ }^{12}$ Deprivation indicators used by Ley and Smith (2000) include: welfare dependency, family instability, high unemployment and crime (Ley and Smith 2000: 37)
} 
Gradual gentrification is by-and-large a process that displaces poorer or working class people from one area to another area in a city; in Toronto it usually displaces people from urban centres to suburban ones (Ley and Smith 2000: 37; Slater 2004: 305). Davidson (2007: 493) argues that this is largely a globalized process that is occurring, because of capital interests from land developers who usurp dilapidated public housing or land to establish more 'cosmopolitan' looking residential complexes for middle and upper-class people (Davidson 2007: 498). As such, over the last decade there has been growing gentrification in the Toronto downtown corridor, where newly erected condominium complexes are next to dilapidated social housing complexes. For local governments, gentrification allows a quick opportunity to boost finances for crumbling municipal infrastructure projects. Slowly, Toronto's poor, marginalized and largely immigrant population has been pushed to the suburbs along with a large number of affordable public housing complexes (Ley and Smith 2000: 47). Such housing complexes are often described as deprived, i.e., they experience higher levels of crime, poverty, poorer infrastructure, cyclical unemployment and lower educational levels.

Over the last few decades many Canadian women have been advancing in terms of career opportunities and wealth creation, more than ever before. The ability to purchase condos in large urban centres, such as Toronto, is therefore increasingly becoming a reality for single, largely Canadian-born women (Skaburskis 1997: 278). However, the same cannot be said about women of new immigrant communities. In communities where poverty is a significant problem, the reverse is true and there is a trend towards displacement and ghettoization (Ley and Smith 2000: 48). Life for single mothers and women, especially those who rely on government support, is increasingly 
becoming polarized in comparison to those women who are achieving significant gains in terms of career prospects and hence increased mobility (Skaburskis 1997: 316).

Therefore, while significant advancements are being made by one group of women (Skaburskis 1997: 316), the same is not true for largely new immigrant and racialized groups of women (Evans 207: 33; Teelucksingh and Galabuzi 2005: 8). Therefore, it can be said that gender inequality is not the only dimension at play when considering how lack of adequate housing affects poorer women, who are largely women of colour.

Along with housing, there is a significant need for accessible transportation. Only two of the women on Ontario Works social assistance owned a car, and that is because they qualified for ODSP disability payments. For most of the other women, owning a car was not an option if they were receiving social assistance payments, because of the financial burden for car insurance and maintenance. Having a stipend for transportation would relieve a lot of the women's stress. Many women talked about how getting to doctor's appointments or the grocery store would often require one or two buses and would take upwards of two to three hours in transportation time. For women with younger children, they would have to consider the implications of not having accessible childcare and leaving their children while they made their shopping trips or went to their appointments. Veena provides an example:

With my kids it's so difficult to go around. I have to think about going out in the snow to get milk and leaving my kids at home and half the time my hands don't work [she is arthritic]. (Veena, February 21, 2006)

Under Ontario Works social assistance support, survivors are often urged to rush back to work without fully recovering, or well before their divorce proceedings are underway. This places a significant amount of pressure on immigrant women, because of 
ongoing mental health issues, physical health issues, lack of childcare, and due to the lack of recognition of their educational qualifications. Though survivors receive very little financial support from Ontario Works and/or ODSP, their prospects for acquiring gainful employments are very slim. Most employment opportunities for immigrant women come in the form of precarious (short term, low salaries) employment. Housing and transport create a challenge for women because of the relative long distance of social housing complexes to shopping centres, cheap groceries, health care providers and childcare services.

\section{Legal Aid:}

Like funding for other social programs, funding for legal aid also suffered in 1996, when the Canada Health and Social Transfer (CHST) program replaced the Canada Assistance Plan (CAP) (Day and Brodsky 2007). This made it harder for women to obtain legal aid for civil cases such as divorce, because criminal cases took priority over civil cases. Overwhelmingly, the women interviewed cited legal aid, lawyers and the legal system, as being key areas in need of improvement. The main areas they cited related to: 1) the unfair requirements to receive legal aid;2) the neglect of their lawyers; 3) the injustice of having unpaid labour not count towards their entitlements; and, most of all, 4) the length of time the legal aid process took. Legal aid is an area that both the counselors and survivors alike felt needed drastic improvement.

Legal Aid in Ontario puts women survivors of abuse in a very difficult 'catch-22' situation, as women cannot successfully get legal aid unless they have less than $\$ 1600$ in their bank account at the time of their need. Sixteen hundred dollars is not nearly enough 
money to survive even a month with several children, let alone get legal assistance if you happen to have only a few dollars more than that amount. Due to very lengthy divorce proceedings, many women talked about having to switch between a private lawyer and one provided to them through legal aid, because of the monetary restrictions placed on those using legal aid. Salima talked about her dilemma in getting the same lawyer when she sought legal aid:

First time around - I had legal aid. I didn't have any problems. Then we sold the house and I didn't qualify for legal aid so I couldn't do anything, I had saved some money from the sales of the house. When my money was completely gone then I was able to get legal aid and an interpreter. The first time it was fast, the second time there was some money in my bank - so they didn't give me any help. But the third time - when I applied to welfare - then the welfare people got me legal aid. I found my old lawyer that I had the first time. (Salima, May 11, 2006)

Legal aid, the cases that I know - that it's hard to get legal aid in [the region in the GTA where the agency is located] - or Ontario even, I don't know. And with women too, like they don't have - those that have money that they have saved up from whatever their jobs were or whatever income they have, they have to use that money up before they can apply for legal aid. You can't have any savings. I think that's really, I don't know, it's wrong because they are put in - they are put in some sort of legal situation they have to get a divorce or they have to file for custody or whatever, because they are in say some violent situation with their husband. Yet they have to waste all of their money. I don't know, I would love it if the husband had to pay. Well, whoever the abuser is - I shouldn't say that because we've had situations where the wife was abusive too. (Tanvi, February 13, 2006)

Many of the women felt that the lawyers never really listened to what they were saying, that the circumstances of their lives did not matter to the case. Other women who had used legal aid services said that they felt that the cases made by the lawyers were very 'cookie cutter', and not tailored to their lives, that the details of their lives did not matter. Farzana, who had some money saved up, hired her own lawyer, and after spending over $\$ 8000$, she ran out of money and had to resort to legal aid after waiting several months. 
Along with their experiences with legal aid in Ontario, several women commented about the inequity of not having their unpaid work contributions recognized in regard to financial compensation during divorce settlements and alimony payments in a court of law. Such contributions include, but are not limited to, raising children, cleaning, laundry, cooking and often their out of home paid work, which was often used to cover daily household expenses. Such contributions required time, resources and effort; yet, the injustice was that neither their lawyers nor the legal system recognized these efforts. As Alpana put it:

The legal system needs to support us because we may not be contributing to the house financially, but we do contribute in the house - we do a whole lot in the house. We do the cooking the cleaning, every single thing! All my husband did was when he got home was sit down, put the TV and relax on the couch. And he wouldn't even wash his hands he would just use a napkin. He wouldn't do anything so I feel like I did everything. How can he take something from me just because it was bought with his money [in reference to their home and belongings]? How can he just take it back? (Alpana, February 20, 2006)

While women are undergoing legal proceedings there are many other concerns that they need to take care of such as finding childcare facilities, determining who gets custody of their children, how they will get from their home to the courthouse, etc. The period of formal legal separation is one that is extremely stressful for women. It is also a time where men can be their most manipulative, using legal and non-legal means, and most women live in fear of what may happen during this time because they are forced to still communicate with their husbands through their lawyers or proceedings. Considering that most of the women I spoke with said that their divorce was still taking place, the services under legal aid provisions are very poor and leave women very vulnerable to abuse and violence from their husbands. 
As Nancy explained, the most common complaint about legal aid were the long wait times associated with receiving assistance:

The legal aid lawyers should be helpful - they should be able to arrange for earlier case trials. The legal aid lawyers should have a time limit. They need to arrange for earlier dates. Why do they keep the cases hanging? If someone dies while they are waiting for their case - then it's not worth it...(Nancy, February $21,2006)$

In sum, women face many challenges in the transition from living with an abusive partner, and the challenges they face go beyond just the psychological and emotional trauma and impact their lives in very material ways. Neoliberal policies affecting welfare, social assistance, housing, urban planning, shelters and legal aid can often exacerbate women's negative experiences and create a vicious cycle of poverty from which women often find it difficult to escape. Some of the survivors have described this experience and the limitations that they face in achieving financial and material independence due to regressive state policies, such as workfare, as a form of abuse itself. The next section describes how women are impacted in their social lives and health during the time they experience wife abuse and after they separate from their husbands.

\section{Part 4: Women's Current Social Situation:}

After experiencing wife abuse and separating from their spouses, women experience many documented health and emotional problems. Their social life and social status are also affected, and they face many hurdles in creating friendships and networks within the larger South Asian community. This section illuminates some of the challenges that women face in terms of their health and socially. Finally, this chapter 
discusses some of the future goals of women and their recommendations for improving services to assist with certain aspects of their transition.

\section{Health:}

Depression is a shared ailment among survivors of wife abuse. According to a multi-country WHO study, women who have experienced domestic violence report a range of health complications:

Epidemiological and clinical studies have noted that physically and sexually violent acts by intimate partners are consistently associated with a broad array of negative health outcomes, including gynaecological disorders, adverse pregnancy outcomes, irritable bowel syndrome, gastrointestinal disorders, and various chronic-pain syndromes. Abused women have more physical symptoms of poor health, and more days in bed than do women who have not been abused. Physical and sexual violence have also been associated with psychiatric problems, including depression, anxiety, phobias, post-traumatic stress disorder, suicidality, and alcohol and drug abuse. (Ellsberg et al. 2008: 2)

According to a recent study by the World Health Organization (WHO), mental health disorders affected more than $50 \%$ of the women who had experienced some type of domestic violence (Ludermir et al. 2008). According to other research, depression is common among women who have experienced domestic violence, affecting $74 \%$ (Tolman and Rosen 2001).

Nearly all of the study participants talked about how severe depression prevented them from achieving all the things that they hoped for. While I did not inquire whether women were clinically depressed or whether they were referring to general feelings of depression, at least six of them voluntarily talked about how they continued to suffer from clinical depression. Some women talked about it in the past tense, and still others, like Sidra, faced recurring and ongoing symptoms of depression over years. Sidra talked about how clinical depression prevented her from getting a job, whereas in her home 
country she had worked in a high-profile government position. According to other studies, most survivors claim that depression is the biggest barrier to their employment efforts (Tolman and Rosen 2001). While mental health issues are heavily stigmatized in the South Asian community (Fischbach and Herbert 1997), the survivors in this study were very frank in their discussion of these issues.

Many of the older women, like Nancy, Veena and Nilam, talked about how they occasionally felt pain in the same areas where they had been kicked or hit in the past. Aches and pains were very common among the older women in this study, which is consistent with WHO findings (Ellsberg et al. 2008). Several of the older women had other health complications such as diabetes and high-blood pressure that may or may not be related to their wife abuse.

\section{Living in Fear After Separation:}

Despite their separation from their spouses, at the time of this study many of the women were still undergoing a legal divorce from their husbands. Due to the problems associated with legal aid, many of them were still waiting for their official divorces. Though many of the women had been separated from their husbands for at least two or more years, they lived in fear of their ex-husbands, and had an overarching sense of mistrust in their dealings with their former spouses.

Since many of the women have had children with their husbands and exhusbands, their husbands still play a part in their lives, especially when custody is shared. For example, Sidra, who separated from her husband four years before the study was conducted, must often rely on her husband to take care of her children when she has a 
depression relapse. However, she constantly fears that her husband will use this against

her in his attempt to win full custody over their children:

Now I am so scared that he can use this against me. I'm not doing anything wrong - I'm attending all my programs. I mean if you look at the good and the bad in it he really doesn't have any proof that I'm not looking at my kids properly.

Because I'm taking my medication - seeing my support worker, seeing my psychiatrist so there is no proof that I'm not doing what I'm supposed to do - but in the back of my head he's such a devious guy that I could never trust him.

(Sidra, February 20, 2006)

In Sidra's case, her ex-husband had tried to gain custody of their children by reporting her to Children's Aid on several occasions, by saying that she was beating their children. Her fear, therefore, is not unfounded. To complicate matters, Sidra also suffered from constant depression and she was often worried about her mental health being used against her in court so that her husband could acquire full custody of their children.

Like Sidra, Nancy lived in fear of her husband, although she feared more for her life than for any legal ramifications. Nancy explained that, immediately after leaving her husband, she moved in with her sister and her brother-in-law. Within months, her husband hired 'thugs' who beat up her brother-in-law one day when he was leaving for work:

He had my brother-in-law beaten up when he went to work at 6 am in the morning. The thugs were standing there from before, and then my brother-in-law had to get surgery. The three men beat him with metal bats and such. So that's when I realized that because I live with them - they incur problems too. So, I left them, too, and separated from my husband. At that point I went to a shelter. (Nancy, February 21, 2006)

It is a common strategy for abusive men to assault or threaten to harm people who support or assist women who leave their relationships (Thiara 2010: 171). This strategy serves to make women feel guilty for getting others involved (and women usually refuse 
further help from these people) and it intimidates their family and friends from further aiding them in the transition process.

Nancy's case would seem remarkable, except that Nancy was not the only woman who claimed her husband hired 'thugs' to beat up her family members in order to intimidate her. In a high-profile incident that left her sister-in-law permanently disfigured, Salima's husband hired thugs to beat the family members who helped her out, four years after her separation:

[A] lady [who was standing at the door] wanted to come in - my sister-in-law asked why she needed to come in - but my brother let her in anyways. As soon as they did this - she made a hand gesture and the two men ... came barging in. They all came in and sat down with the family. All of a sudden one of the men started hitting them with a sword. And they were unconscious for a while. The man chopped off a few fingers from one of my sister's hands and then a few from the other and he also slashed my brother's ear. Luckily my brother's ear was saved and they could put it back together, but some of my sister-in-laws fingers are permanently damaged. (Salima, May 11, 2006)

In Salima's situation, her constant interaction with her husband over several outstanding matters (such as the divorce proceedings, custody of their children and child-support payments) is what she believes led up to this incident. This incident occurred despite the fact that she was no longer living with her brother and sister-in-law at the time, but resided in a separate apartment. However, this assault took place shortly after Salima addressed her husband's interactions with her son, and the children subsequently stopped visiting him. Salima stated that whenever her son would visit his father, "His father would teach my son something against me and when my son would come back home - he would take it out on me." Even now, she is fearful of interacting with other people, and when I originally spoke to her, she assumed that I might have been someone hired to find out more information about her for her husband. 
In an even more high-risk situation, Veena was relocated under police protection from another Canadian city to Toronto. In her situation, several family members of her husband's own family were threatened and assaulted by her former husband. Talking to me she was very worried that someone would discover her whereabouts, because her husband had relatives in Toronto. In December of 2006, his restraining order had already expired, and though she has attempted to renew it, she worried that it might be too late as he was able to find out that she lived in Toronto.

Because of their ex-spouses' harassment and assaults against their family members, women such as Nancy, Veena and Salima are further isolated from those whom they love or who love them, because they have to live in constant fear for their lives. This adds to the mental strain on their lives, and makes it difficult for them to achieve their goals or even consider working, due to a fear of being assaulted on their way to or from work. In both Nancy's and Salima's cases, their family members were attacked on their way to work or during their time off from work, i.e., they were targeted and timed attacks where no one could prove who the assailants were.

\section{Social Ostracism from the South Asian Community:}

It is important to recognize that there have been few studies conducted on South Asians and divorce (Gupta 1999: 195). As this area is understudied, it is difficult to assess the larger context and cultural stigma that South Asian women face, as most women do not opt for a divorce or formal separation from their abusive partners because of the material and societal benefits from marriage and the social stigma that may occur from a formal separation let alone a legal divorce (Gupta 1999; Rao 2002). 
Sangeeta Gupta further writes that, "Divorce strikes at the very heart of the AsianIndian patriarchal system. By contemplating divorce, a woman of Asian-Indian origin is challenging the feminine gender roles established by this system - roles of submissive and subordinate daughters, wives, and mothers" (Gupta 1999: 194). In this research, the majority of women talked very intimately about how a formal separation from their spouses increased negative speculation about their personalities and behaviour. Their husbands' friends and relatives, who had befriended them during the course of their marriage, now turned against them, as Alapana explained "He's constantly being told by his family and friends that I am not a good person."

Similarly, Sidra remarked:

My children's dad's [i.e., husband's] friends automatically became my friends when we got married. But when we got divorced and separated, his friends automatically took his side. But I have more friends now - because I have met them in different ways. (Sidra, February 20, 2006)

Though the women in this study were from different religions (mainly Hindu and Muslim), irrespective of their religion, divorce disproportionately stigmatizes women in comparison to their partners in South Asian communities (Rao 2002: 549). This stigmatization occurs not just by their immediate relations but also in the larger community. Many of the women repeatedly stated that their invitations to community gatherings dramatically reduced after they left their spouses. Several of the older women talked about being stared at, at weddings and other formal functions. Nancy mentioned that she often felt that at weddings people believed that her separation from her husband might inspire the bride to commit a similar offence. She likened the treatment that she received at social gatherings to how South Asians often treat widowed women, who are widely known to be socially ostracized (Cohen 1998). 
More commonly, other women talked about how many men and women at social and community events gossiped about them. People spread rumours about their sexuality and why they might have 'really' left their spouses. Gossiping was even more exaggerated when both the wife and husband had mutual friends. Indirectly, being a single mother influenced other women's decisions to attend events, as it might have an impact on how their children (especially female children) were perceived in the community. Veena, who received social assistance, talked about how attending social functions decreased as she and her children never had any appropriate clothing to wear to weddings and other social gatherings. They had to take whatever came through the service agencies or purchase clothes at second-hand stores.

In addition to being met with social ostracism at community and social events, many of the women reported that they encountered incidences of sexual harassment within their communities, largely because men were aware of their status as a single woman.

Married men make passes at you. It's basically sexual harassment. One man said to me, "No one would live in a house with a witch like you." I basically don't have any protection against anyone's insults. If you said that to a married woman, you couldn't get away with saying "witch and crazy" to their face. Because I'm not married people feel they can treat me like trash or a piece of shit. I have found speaking up and being nice to people makes a difference. (Asha, February 27, 2006)

Such experiences with sexual harassment furthered the distrust that women felt towards men and even other women:

But when I met any guys they just wanted to take advantage of me - just take advantage. Nothing, they didn't want a real relation - just sexual relations. I just got tired. Now I know the difference between a real situation and just display friends. I just gave up that situation. (Meena, January 17, 2007) 
Sexual harassment further prevented women from attending social events in their community.

As we have seen, South Asian women are largely isolated when they arrive in Canada upon marriage to their husbands. During their marriages, their husbands use isolation as a means to control them, and after their marriages women are again isolated due to community disapproval of their marital status. Thus, loneliness and isolation characterize several consecutive life stages for these women after immigration, as a product of their combined statuses as immigrant women and survivors of wife abuse.

\section{On Moving Forward and Creating New Social Networks:}

One of the ways many women were able make important gains socially was through the SAWOs that they attended. Through the SAWOs the women were able to meet, interact, befriend and learn from other women who also used the services of the agency. Nancy talked about these positive aspects:

Yes, before I used to think I was the only one who was sad. How can I live like this? But then I see others - and see [that] she's better than me - she can even take her children outside. And she went through the same thing [as me]. If you look at someone else, you can get a little confidence, then you feel a little bit better. Then I am able to get up in the mornings; otherwise I always feel like what am I supposed to do when I get up. Sometimes I am just lying around until $11-$ $12 \mathrm{pm}$. Why bother getting out of bed at this time? (Nancy, February 21, 2006)

For some of the women who were single and childless, they felt that not having children was also an obstacle in terms of networking. Asha felt that if she had children, she might have been able to meet other parents, but concluded that having children would also be far more costly: 
Sometimes it might be better to have kids, though, because you get a network by default, if you take the kids to birthday parties. You have to get a better home if you have kids and you have to make more money. (Asha, February 27, 2006)

It was very clear from these interviews that of all of the women who used the services of the SAWOs, many did find other South Asian women friends through these interactions.

The other aspect of this interaction with other survivors of wife abuse was that nearly all of the women that I spoke with also gave an indication of becoming aware of the issue of the gendered implications of wife abuse. Women often discussed this when they indicated their desire to reach out and help other women in their situation. In fact, even one of the counselors had undergone a difficult marriage. The desire to help other women manifested itself in various ways. At least two of the women, Chandrika and Kruti, actually took up jobs in the social assistance field - one was working as an interpreter, and the other was working as a job placement counselor.

Others, like Sidra, talked about how they wanted to go back to school and take social work classes:

You're going to laugh - but I want to become a social worker. I want to do it. You know what I signed up at [name of institution], I did the exam, they accepted me I was all ready to go. I couldn't go through [with it] and with what OSAP was paying me - If I didn't have a job I would have had to quit to go full-time. (Sidra, February 20, 2006)

Meena used the SAWOs services and also volunteered her time there.

I have a volunteer job there [at a SAWO]. I took some ESL, took it at near my place - there is an ESL class. I take it 4-5 days a week. (Meena, January 17, 2007)

By using these services, women came to feel the need to address problems that they felt were not unique to them but fairly common among women. 
Prior to the interview portion of my research and as a feminist researcher myself, my personal interest in this study was to examine the kind of debates other feminist social scientists had around feminism and service provision, namely about whether or not "feminist counselling services" were mandatory in empowering women or not. In her 1998 study on the tensions between providing counselling services and using a feminist framework to counsel women, Vijay Agnew talked about the difference between immediate 'practical' counseling needs and 'consciousness-raising,' where she concluded that:

A woman who obtains services from a community-based group is unlikely to want to overthrow conventional gender roles; she is seeking help to stop the violence against her. She and the counselor do not debate ideology but devise practical strategies for her individual life situation. (Agnew 1998a: 157)

Unlike Agnew, Kimberlé Williams Crenshaw (1994) believes that feminist counselling services are not necessarily beneficial in assisting women of colour who are wife abuse survivors. In fact, she believes that feminist intervention can often be an isolating experience for women of colour survivors, and that culturally sensitive support services may be far more beneficial to assist women of colour:

Women working in the field of domestic violence have sometimes reproduced the subordination and marginalization of women of color by adopting policies, priorities, or strategies of empowerment that either elide or wholly disregard the particular intersectional needs of women of color. (Crenshaw 1994: 107)

From this study, it was revealed that while it is not entirely necessary to have explicitly feminist specific interventions for women to have or develop a high level of feministconsciousness, it can be psychologically empowering for women to know that they are not alone in their experiences of wife abuse and that gender based oppression does exist. 
Women's positive understandings of gender based oppression were exemplified by how women passed on knowledge and strength to other women in their lives, such as: advising their female friends when their male partners were aggressive towards them, referring their friends to SAWOs and other counselling services, motivating their friends, volunteering at the SAWOs and changing their careers to formally work in the social services sector.

In situations where I felt that a woman continually talked about 'women's issues' in a broader macro-level context and where I felt that I had developed a rapport with them I asked if they considered themselves 'feminists', and the three survivors whom I asked, responded affirmatively to this question.

I would like to be a counselor. Women's counselor. Women, we are staying home - and they are not used to be[ing] alone. I want to try to identify which ones have problem - and how can I solve their problems. In my experience and others' experience, I try to understand their problems. I think it's better for me. If you have a good family you have everything, if you don't you have nothing. If you want to be a happy woman, you need a happy family. That is why I try to solve these kinds of situations and problems. (Meena, January 17, 2007)

Near the end of the interviews, I asked the women about how they felt about the future and what goals, if any, they had. The responses varied depending on their mental health, whether they had children, and their confidence regarding employment and education. For example, Salima wasn't sure about what the future would bring - citing her future goals to be more about destiny. However, she talked about how she now handles difficult situations with her family, her ex-husband and her children and she says she is a different person: 
I think that counselling, however, is not necessary this time - I manage to stand up to my own problems now - I try to get a way through them, and get out of my problems. I comfort myself and tell myself that it happens to many other people, not just me. I was on therapy and with medicine at the beginning - but the therapist was very far, and it was hard for me to travel, so I had to stop going. Now I think I can do it myself - and I am stronger. I should be able to do it now. I am not the same as before. Before I was just cursing myself - and blaming myself for everything that happened. Now I am strong. (Salima, May 11, 2006)

In order to get a better understanding of abused women's experiences and survival strategies, I also asked the women a general question about healing and recovery: "What makes you stronger?" Surprisingly, most women responded in a similar manner, stating that it was either their children or religion that helped them to get through their rough times. Often, the response was about how it was hope for a brighter future for their children that kept them going. Many of the women had messages for the other women who may be reading this thesis, which were centred around positive messages of empowerment, such as of the following:

You can only be empowered by your experiences, you can tell this to the women. My parents and siblings used to teach me everything - but I never felt like this was my life, I didn't think it was fair - you made me get married to this guy, it was not my choice... Shatki jo hai apne mein jodke dimag se nikalo - Take strength inside, make your mind firm and get rid of all the things that stop you from your decision. (Salima, May 11, 2006)

If you have one time broken your marriage - if you have some skill - you are never alone. If you are not that skilled, you cannot do that. If you have skills, you can have not just your husband, but it could be your father and brother mentally abusing you. Women need to see that they don't need to stay in that situation, they can leave the person if they are not a good person. She should just leave. First [marrying a] husband and then [learning to become] friends is impossible. It has to be first friend and then husband. (Meena, January 17, 2007) 


\section{How to Make Improvements According to the Counselors and Survivors:}

Counselors felt that the problem of domestic violence was systemic, and that the macro level legal, educational, communal, and health arenas need to address the power imbalance between men and women. They also suggested some small, immediate changes at the micro level as well. Since women are often forced to leave abusive relationships quite suddenly, with little more than the clothes that they are wearing at the time, one of the counselors suggested that there needs to be a system in place where counselors should be able to provide a small amount of money to the woman for immediate needs, such as transportation and food. At the moment of evacuation, crisis intervention workers are forced to either watch women face immediate hardship, or to give them a small amount of money themselves. Sometimes the workers are not compensated for this financial support to individual women.

One of the other main areas identified for improvement repeatedly mentioned by the counselors was prevention education. As the counselor, Shilpa, explains:

There's no money in prevention, here, there is no money in prevention. I have been trying for 18 years. There is only money in 'after the fact', ... why can't we empower these women before they get abused? We should follow [pursue this prevention work] and it should become mandatory. The problem here is requiring that we adapt something that is very effective. If it still does not happen then at least we have the satisfaction of knowing that we have done prevention work. You know the Catholic Church, if the Catholics have to get married with a license in the church and they have to attend an eight-week marriage-counselling course before they get married, I think it should become mandatory here in this case [of marriages for South Asian women]. (Shilpa, February 16, 2006)

The main problem with abuse prevention education that the counselors cited was that, in general, the government fears supporting it due to the lack of 'visible results'. They do not see the point in investing in something where it is difficult to establish measurable results, or that may or may not be viewed by government (or the general public) as 
making a difference. Also, there is very little space for dissemination of this type of abuse prevention education. Two of the counselors and one of the support workers suggested that religious institutions, which are often the first place of networking for newcomers, disapprove of addressing domestic violence in the community. As Shilpa articulated:

In a lot of battles, religion has been used as a crutch and history has been tamed. And, unfortunately, where woman abuse is concerned, the men [male religious leaders] are just turning a blind eye. (Shilpa, February 16, 2006)

The struggles of women of colour organizing and trying to reach out to their communities have been cited by other feminists as well (Abraham 1995). The nexus of feminism, women's empowerment and the resistance of religious institutions to address violence against women and other women's issues reveals a complex mesh of cultural and religious values that confront South Asian women's growing awareness about their rights, gender issues, and their need to assert themselves against their abusers, in order to protect themselves and their children.

While many of the survivors I talked to found strength to cope in religion, religious institutions have been hostile towards addressing violence against women in their communities. Often in discussions with religious leaders, this antagonism arises from fear of being further stigmatized by the wider Canadian society. As Tanvi explains, there is a "stereotype amongst police officers that all South Asian men are wife-abusers". It is important to recognize that a potential opportunity exists, here, for mainstream feminist movements to investigate and address the positive relationships that might emerge out of pursuing alliances with religious organizations. Within the context of religious and cultural gatherings, alliances aimed at creating wife abuse awareness, 
among both women and men, have the potential to serve as critical sites for education and prevention of wife abuse against South Asian women in Toronto, Canada.

\section{Conclusion:}

There are many challenges that wife abuse survivors face while leaving their husbands and immediately after separation. The women participants in this study repeatedly cited many of the social support services as being areas of primary challenge not only in terms of access to these services but also challenges while using them. These women discussed their experiences with the shelter system, Ontario Works, legal aid, ODSP, counselors, SAWOs and other members of the South Asian community.

The high cost of living in Toronto coupled with the very minimal stipend standards for social assistance relegates women to live in suburban social housing 'ghettos.' The lack of affordable childcare, transportation, and living in suburban social housing at such a distance from centralized goods, services and family members enhances women's feelings of loneliness and isolation. Though women experience a myriad of long-term health problems years after their abuse, they are often pressured to work within a year of their separation from their spouses in low-paying, precarious employment situations, encouraged by Ontario Works.

Survivors and counselors provided short and long term solutions to improve the system for South Asian wife abuse survivors, such as: allowing women a stipend for clothing, food, and transportation immediately after separation, providing long-term counselling opportunities within the SAWOs, creating a woman's social club to allow women to meet with other women in a positive environment outside of a SAWO, not forcing women to work immediately after separation, not making it necessary for women 
to expend all their savings in order to receive social assistance, housing and legal aid, and working with the South Asian community to create awareness about wife abuse and investing in prevention programs.

Survivors had many positive accounts of their experiences with support through the SAWOs, where they were able to network and make other friends. Knowing that other women also experienced abuse and having positive interactions with the counselors helped the study participants to feel empowered and increased their understanding of gendered violence. Most survivors described feeling more confident and expressed the desire to help other women who have experienced wife abuse. 


\section{Chapter 4: CONCLUSIONS AND RECOMMENDATIONS:}

This study was conducted in the Greater Toronto Area with 15 South Asian wife abuse survivors and three counselors, where there are several SAWOs located. Semistructured interviews were conducted usually at the women's residences. While previous studies on wife abuse among South Asians have focused on either gender or culture exclusively or employed an ethno-gender framework (Abraham 1995), this study employed an intersectional (or holistic) and political-economic approach to examine wife abuse in the South Asian community. This study illustrates that there are three main areas that affect women's ability or inability to cope with and respond to their experiences with violence: 1) cultural factors; 2) immigration and social isolation; and, 3) political-economic constraints. In other studies about wife abuse in the South Asian community and also in mainstream discourses, incidences of wife abuse among South Asians are often treated as being unique to aspects of South Asian culture, i.e., incidences of gendered violence are presumed to occur due to 'backwards' cultural practices. These types of media influenced discourses serve to remove the blame from the inherent

problems in our social, political and economic structures by relocating the blame onto cultural differences (Jiwani 2006).

While women are able to exert personal agency in the decisions that may directly impact their lives, they are also embedded in a matrix of socio-cultural and economic realities that often set the conditions for their choices (Kabeer 1999). I believe that this study helps to explain some of the reasons that women may not want to or are not able to leave violent situations. Women in the South Asian community may examine the lives of 
other women who have undergone the process of leaving an abusive husband and they may become aware of the myriad of challenges they face while doing so. I propose that rather than assuming that women are victims of psychological conditions such as 'battered wife syndrome', we need to acknowledge that women, in fact, realize the harsh socio-economic challenges they are up against when taking the decision to stay with or leave their husbands.

Like many new immigrants, wife abuse survivors are doubly discriminated against in terms of race and gender when it comes to employment equity. In order to achieve their desired goals, these women need to have the ability to find work that is in a field that is reflective of their skill and education levels. Not recognizing foreign credentials not only affects the mental health and living conditions of entire groups of people, but it also places a huge financial burden on Canada (Teelucksingh and Galabuzi 2005: 27), because it fails to harness the abilities of people who already possess needed skills and training. Precarious work (short-term contracts, low pay, casual labour) further marginalizes women who are already struggling to make ends meet, and are also struggling in other areas of their lives, and this often leads to welfare cycling.

In order to stop welfare cycling, women need to be allotted a minimum standard of time to recover from their traumatic experiences of abuse, while being given significant counselling opportunities, as recovery is a slow process and specific to each individual. In their Michigan-based study, Tolman and Rosen (2001: 155) recommend that benefits for women survivors of wife abuse extend over sixty months as most women have a variety of different needs and the effects of wife abuse are often long term. The 
needs of survivors are complex and unique and should be assessed on a case-by-case basis.

Neoliberal political and economic values do not affect precarious employment alone, but have become entrenched in most of the social service sector, including social assistance. It is very apparent from the majority of the interviews in this study that support payments from Ontario Works and Ontario Disability Support Program [ODSP] are insufficient, and it is difficult for women even to barely scrape by. In order to make ends meet, and to make necessary, yet unacknowledged expenditures for formal clothing for job interviews, social events, overseas visits to family, or children's school trips, there needs to be more substantial support payments made to survivors of wife abuse and others who rely on social payments.

Neoliberal effects on state policies, such as housing, social assistance, legal aid and employment, complicate women's situation by requiring stringent protocols and applying strict criteria in order to receive assistance. Women need a bare minimum in their bank accounts in case of an emergency. Likewise, women who own property or an automobile should not be penalized by not being able to access support services or legal aid. Their paid and unpaid contributions to building their homes in the form of employment, child-rearing and housework still go unrecognized. Legal aid procedures need to be streamlined in order to get women out of difficult situations sooner. Lengthy court proceedings put women in a vulnerable situation in which they repeatedly come into contact with their abusers.

Most importantly, women's service needs must be assessed based on quality of life needs (Tolman and Rosen 2001), rather than simply expecting that once survivors 
have received minimum care regarding counselling, social assistance and basic employment that they will recover from their experiences. Additionally, the requirement of the Ontario Works - Workfare Program further disenfranchises a group of women who are already at the mercy of the social welfare system by rushing them into finding 'any job' immediately after they start receiving Ontario Works payments. This does not allow women to seek jobs that are in line with their career goals, educational attainment and ambitions. It also forces women to enter precarious employment situations where their salaries are almost equivalent to what Ontario Works benefits offer.

All of the women interviewed in this study experienced some sort of isolation or loneliness. Isolation is experienced at many different levels, and it is exacerbated by women's social housing conditions, immigration regulations and poverty. Gentrification of cities and the displacement of poorer and working families from urban centres disempowers people from civic and community participation. Lack of adequate suburban transportation and the lack of a transportation allowance for those on Ontario Works payments and ODSP make travelling difficult. Women are further burdened with childcare responsibilities due to a lack of affordable childcare facilities, which further limits women's career, education and social networking opportunities.

It is evident from this study that the SAWOs played an important part in the lives of the women who were interviewed. Many of the women participants especially appreciated that counselors spoke their language and had a similar ethnic background. The SAWOs not only enabled women to leave their abusive situations but in some cases provided long-term counselling and support as well. Though many previous studies have debated whether counselling practices need to use feminist principles and feminist 
models of empowerment (Agnew 1998a: 177; Crenshaw 1994) from this study it was apparent that most counselors did consider themselves feminists, and that the methods used to empower women did, in fact, translate into an increase in feminist consciousness among women, whether feminist practises were used or not. In candid remarks after interviews, women jokingly told me not to get married, and then they would tell me about how it felt good to be independent and on one's own. Sometimes they would tell me about the need for women to connect with each other and help each other. Many women even talked about gender roles and expectations, the double standards imposed on women by South Asian society and the larger Canadian society, and how they were not going to settle for less than equality in their relationships anymore.

Although the work of the SAWOs is invaluable in enhancing women's confidence and assisting them in acquiring needed resources, the SAWOs are quite limited in how much they can do for women. The function with constraints about how long they can spend with clients, how many clients they can have, and the types of counselling they are able to provide. While the SAWOs are overburdened they are unable to provide assistance to women for necessary support for childcare, job searches, employment opportunities, and helping women acquire a larger monthly income. Another area that the survivors' felt was also limited through their connection to SAWO services was the opportunity to establish new friendships and networks to help alleviate their loneliness. Most women felt that it was necessary to have a community group (outside of the SAWOs) for women to socialize, rather than going to wellness groups at the SAWOs that focused on their abuse. Women wanted opportunities to meet people with whom they could socialize and whom they could befriend, rather than just articulate their frustrations 
about their experiences with abuse. Through the activities of the SAWOs, women felt that the SAWO space was too restricted to activities that centred on their experience with abuse:

I would like to form a club for women to just get together, an Asian women's club or organization where women can enjoy company emotionally. Women need to cooperate with each other. (Asha, February 27, 2006)

I want to start one centre - where we can call the women where they can stand up for their rights, because there is no centre like that. (Rita, May 22, 2006)

With an expected growth projection of more newcomers and immigrants to Canada from South Asian countries and an expected 28\% South Asian population in Canada by 2031(Friesen 2010), we can already see the growing trend of the colourization of poverty (Teelucksingh and Gallabuzi 2007: 4). Among communities of colour, poverty often has a negative impact on women's mobility (Crenshaw 1994), therefore we might be seeing a further entrenchment of the colourization of violence against women too, unless support services and prevention programs are set in place.

While this study examined the experiences and perspectives of South Asian wife abuse survivors in regards to how they perceived the social assistance and welfare programs, there were some limitations to the study and also future opportunities for research. First of all, two of the women were so traumatized from their experiences that they were suspicious of people at large including myself ${ }^{13}$. As a researcher with very little knowledge of the day-to-day lives of these women and having had no prior contact with them, they would definitely have difficulty trusting an outsider like me. Secondly, no men were interviewed in this study, and, in order to get a broader understanding of

\footnotetext{
${ }^{13}$ One woman assumed I was a private investigator (or spy) and another talked about how she was concerned someone was stealing her peanut butter when she was away from home.
} 
male abusers, it would be important to examine men's (abusers and non-abusers) perspectives of wife abuse and gender issues as well. It would also be possible to continue with interviews that examine women's post-counseling experiences because the current literature on it is very limited. Finally, it has been found that research regarding wife abuse and immigrant populations largely focuses on urban centres, where for statistical reasons it is easier to gather data (Waccholz and Miedema 2000: 302) because larger populations of immigrants reside in urban centres making it easier to recruit more participants. Immigrant women living in rural settings face another element of isolation in addition to that experienced by their urban counterparts, and it would be interesting to see a study that focuses on women who receive support in rural settings. More studies are definitely needed on changing gender roles, as well as the social ostracism that South Asian women face around divorce and separation. 


\section{Appendix A: Information Sheet sent to SAWOs and Distributed to Participants}

\section{Project Abstract:}

This research examines the challenges, constraints and opportunities that South Asian immigrant women who utilize the services of second stage support programs face after their completion of group sessions. Based on interviews with victims/survivors of violence, this project explores how women evaluate criminal justice system responses along side social service and community responses. It will explore systemic barriers that South Asian women may experience. It will investigate the multiple benefits of cultural and language specific domestic violence support programs. This research will contribute to a more holistic understanding of this issue by exploring women's own experiences of interacting with the legal system, welfare agencies, shelters and culturally sensitive support services. By understanding women's own experiences we can contribute to further understanding how women are empowered, and what areas women need the most support in. Thus, this paper also examines wellness and the empowerment of women. (A. Agrawal)

\section{Project Objectives:}

- To understand the importance of women's sense of empowerment, in their own words

- To learn from women about which areas they need the most support

- To understand how women's idea of gender roles has changed after they have been supported

- To understand the importance and benefits of culturally sensitive support organizations

- To contribute to an area that has been researched very little, i.e., women's sense of empowerment after support intervention

\section{Project Requirements:}

I am seeking to interview at least 10-15 women survivors of domestic violence. I am also seeking to interview at least 3-5 counselors/facilitators of wellness groups or domestic violence counseling.

\section{Can I be of Assistance to you?}

Please find my attached resume. If you feel that there is any way that I can assist, please let me know I would be happy to create: information pamphlets, volunteer at events, help in other ways. As an outsider, I would also be willing to ask questions that counselors such as yourself might not get the opportunity to ask your clients. Please let me know if you would like for me to add any questions in my research.

\section{Research Methods:}

- Interviews will be 1-2 hours long. 
- The interviews will be very informal and unstructured, i.e., questions may vary from a person to person basis, depending on the interviewees comfort level

- All information will be kept entirely confidential, and will be stored in a secret location.

- Clients of organizations will be compensated at $\$ 15 /$ interview and given two transport tokens.

Thank you so much for your time!

Please feel free to contact me at:

\section{Researcher: Anita Agrawal}

Or my thesis advisor at:

Dr. Jen Pylypa

Department of Sociology and Anthropology, Carleton University

1125 Colonel By Drive

Ottawa, ON Canada

K1S 5B6

Ph: 613. 520.2600 Ext. 6329 Fax: 613.520 .4062

Email: jpylypa@connect.carleton.ca 


\section{Appendix B: Consent Form}

\section{Consent Form (ENGLISH VERSION ONLY): \\ "Defining Wellness: South Asian Women Discuss their Experiences About Second- Stage Family Violence Support Groups in GTA".}

I, have been asked by Anita Agrawal, a Master's candidate in Anthropology attending Carleton University in Ottawa, Canada, to participate in an interview for her M.A. thesis on South Asian women's experiences with domestic violence support groups. Anita Agrawal is a student and is not conducting this research on the behalf of any government or non-governmental agencies. This research project has been approved by the Carleton University Ethics Committee.

I understand that the purpose of this research is to understand my views about the benefits/drawbacks of such services and how I have benefited/been harmed by these services. Questions will address primarily my personal experience with South Asian domestic violence support groups.

I understand that my participation in this research is completely voluntary and I may choose to withdraw at any time during the interview or research process, prior to the final thesis draft submission. At any point that I choose to withdraw from the research study, I can contact the researcher directly and ask that my comments be removed from the study.

I understand that I have the right to anonymity and that no specific indicators regarding my ethnicity, my age, my religious or academic background will be mentioned. The researcher will ensure that my responses will be addressed in such a way that my identity is kept confidential in the research report.

I also understand that all research data is kept in a secure, locked cabinet to which only the researcher has access. This research data will be kept for an indefinite time period in this location, and may be used by the researcher in future conferences and/or publications.

The interview process will last approximately one to three hours at a mutually convenient time and location. The interview may be recorded on a tape-recorder. Once the tape has been transcribed it will remain in another locked cabinet.

I may receive an electronic copy of the Master's thesis upon request, by May 2006.

If I have any questions regarding the research, I may inquire with the researcher or her academic advisors: 
Thesis Advisor:

Dr. Jen Pylypa

Department of Sociology and Anthropology, Carleton University

1125 Colonel By Drive

Ottawa, ON Canada

K1S 5B6

Ph: 613. 520.2600 Ext. 6329 Fax: 613.520.4062

Email: jpylypa@connect.carleton.ca

Any questions about my rights as a research participant, may be addressed to:

Chair of the Research Ethics Committee

Prof Antonio Gualtieri,

C/O Office of Research Services

Room 511A Tory Building, Carleton University

1125 Colonel By Drive

Ottawa, ON Canada

K1S 5B6

Ph: 613. 520.2517 Ext 7434 Fax: 613.520.2521

Email: ethics@carleton.ca

I permit audio-recording of this interview:

Yes

No:

My Signature:

Date: 


\section{Appendix C: Sample Interview Questions}

\section{Sample Interview Questions for primary participants (women who have used counselling facilities and are first-generation immigrants):}

NOTE: Questions will be slightly modified in cases where women are second generation immigrants.

1) Family Background
a. Do you have any siblings?
b. Where in India/Pakistan etc... Are you from?
c. Was it a small/medium town or was it a city?
d. What occupation(s) were your parents involved in? also ask about her - if she is old enough to have worked before immigrating
e. When did you get married?
f. How old were you?
g. Which school did you attend? When did you attend until?
$\mathrm{h}$. What were the major tasks of the women in your household? Did they work in paid employment (either at home or outside of the home?).
i. Did you ever plan on working before you came to Canada? Did you work in India/Pakistan etc..? (Will only be asked if she started working after coming to Canada).

2) Immigration Experience
a. When did you move here?
b. When did you make the decision to move here? ... Why?
c. What was it like to move here? What was hardest for you about living in Canada, at first? Is it still difficult for you/in what way?
d. Who helped you most when you first came here? In what ways?
e. Do you think life is harder for Asian women here, or 'back home'? In what ways is it harder? In what ways is it easier? (probe: financially, in terms of social support, isolation, etc. E.g., Ask her if she feels more isolated from friends and family here or not; Are the money problems greater or worse, etc.)
f. Do you think that marriage is harder for Asian women here, or 'back home'? In what ways is it different - having a good marriage - in the two places?

3) Social Support Networks

a. Do you have any immediate/extended family in Canada? In Toronto?

b. Did you have any friends here when you migrated?

c. Do you have friends here now?

d. Who do you socialize with? Who do you go to for help - e.g., with money, childcare, personal problems?

4) Current Living Situation

a. Where do you currently live?

b. Is it a house? Is it an apartment?

c. Who do you currently live with? (probe: Does anyone else live with you?)

d. Do you have any children? Do they live with you? 
e. How old are they?

f. Everyone who uses this service has had some difficulties with a boyfriend or husband. Do you still see this man sometimes, or are you completely separated from him now? How long have you been separated from him? Are you still having difficulties with him, or is that over with now? (This question will require sensitivity-follow up to the degree that she seems to be comfortable with it. If she is willing to talk about her relationship with him, then let her tell you her story. If she doesn't seem to want to go into details, then move on to section 5

5) Access to Services

a. How did you learn about this agency? Friend/Family/neighbour/police/hospital/community org?

b. Was it easy to find out about the agency?

c. Was this the first agency whose services you used? (or was it a referral from another agency?).

d. How long ago did you first come here/use their services?

e. How did you feel about coming here the first time?

6) Use of Support Services / Experiences with them

a. What did you expect when you came here? What did you expect they would do for you, or tell you? Did you get what you expected?

b. What kind of support did you receive at this agency? What did they do for you? Was it a group session? Was it an individual one-on-one session? probe: Did they do anything else to help you?

c. What was good about coming here, what did you like/find helpful? What did you find was not helpful about what they did? Were you disappointed about anything - like you hoped for something that you didn't receive?

d. Were the counselors helpful to you? Were they familiar with your cultural background? Your language? Were the counselors sensitive to your needs?

e. Is there any particular counselor who you like more than others? If so, why?

f. Do you feel better after receiving support at the agency?

g. Do you feel worse after receiving support at the agency?

7) Support Needs

a. What kind of support do you still need? What do you think they should do differently to help you, or to help you more?

b. Has the kind of help you need changed since you first came here? (This question is only relevant if they have been connected to the agency for awhile )

c. Are you currently working? If so, what is your current occupation?

8) Empowerment and Future Goals of Clients

a. What are your future goals?

b. How have your goals changed with time? Were these the same goals prior to receiving help at this agency?

9) Service Needs 
a. How do you think that the services of this agency can be improved to better help you?

b. What are they still doing for you now? Do you think there is anything that the agency can do now to help you with your life?

Is there anything else you think I should know - about how to make this agency more helpful to you?

Do you have any question for me? 


\section{Sample Interview Questions for secondary participants (counselors and facilitators of support groups):}

NOTE: Questions will be slightly modified in cases where women are second generation immigrants.

1) Family Background

a. Where in India/Pakistan etc... Are you from? (probe for rural, urban, etc.)

b. What occupation(s) were your parents involved in? (Determines class background?)

c. What is your highest level of education? Which University/college did you attend? Was that in India/Pakistan/Canada?

2) Immigration Experience

a. How old were you when you migrated?

b. When did you move here?

c. Why did you make the decision to move here?

3) Current Living Situation

a. Which neighbourhood in Toronto do you currently live in? (indicates class)

b. Do you have any children? How many?

c. Are you married?

d. Do you live with anyone besides your children/spouse? (do they have similar living arrangements as their clients)

4) Employment

a. How long have you been a counselor?

b. How did you get interested in this area? What attracted you to this particular agency? What made you interested in this line of work? How did you decide you would like to counsel women?

c. Was social work your first profession (I have learned that many women are not trained as social workers - some are trained in marketing)?

d. How did you learn about this agency? Friend/Family/neighbour/police/hospital/community org?

e. Was it easy to find out about the agency?

f. What kinds of things happen at this agency? What are the different kinds of work you do/services you offer as an agency?

g. What is the organizational structure of the agency? Are you a nonprofit/charity?

$\mathrm{h}$. Who are your primary funding bodies?

5) Counselors work:

a. What exactly is your job title?

b. What kinds of work does your job entail?

c. How many languages do you speak? Which ones?

d. Do you only counsel women in said language group? Or do you counsel them in other languages too?

e. What is the hardest part of your job? 
f. What do you find to be the most fulfilling about this job?

g. What was your main training for this job, besides your 'formal education' (university) - i.e., did you have special courses or on the job training, etc.

h. Do you have to train frequently? What kinds of additional training do you have to do?

i. What training manuals did you use for training? May I have a look at the materials you used?

j. What would you need most to help you to help women better - e.g., more funding? more counselors? Ability to offer other services? What would you like to be able to offer or do that you can't?

$\mathrm{k}$. So what do you think is the biggest constraint that limits what you can accomplish here? - that you would like to see change?

1. In what way do you think this agency helps women most?

6) Participants:

a. Who do you think primarily uses the services of this agency?

b. How often do you do violence counselling work?

c. Where are women usually referred from, when they come in? Is it hard for women to come to places like this? Why do you think this is so?

d. What is the ethnic/language/class background of the women that usually come in?

7) Theoretical Viewpoints:

a. I've studied a lot about feminism, the need for women to be more empowered in society, etc. Do these ideas influence the way you work, are they useful for you? IF SO: How so? Is it part of your training to talk to women about 'empowerment', etc.? In what way do you use these ideas?

b. Do you think feminism is important in the line of work that you are involved in?

c. Do you think that it helps/hinders the women that you assist in your line of work?

d. What do you think are the causes of violence against South Asian women? - do you think they are the same as the causes of violence for all women in Canada, or are there specific differences/issues affecting the women you work with?

8) Support Needs

a. What do you think women need the most in terms of support?

b. Do you think the women who receive these services feel empowered after they receive help?

c. Which areas do you think women need more support in?

d. Which areas do you think can be improved?

e. Which areas do you think women benefit the most from?

f. What do you think the number one challenge for women who come in seeking abuse counselling is? 


\section{Bibliography:}

Abraham, Margaret

1995 "Ethnicity, Gender, and Marital Violence: South Asian Women's Organizations in the United States." Gender \& Society 9(4): 450-468

2000 "Isolation as a Form of Marital Violence: The South Asian Immigrant Experience." Journal of Social Distress and the Homeless 9(3): 221-236

2005 "Domestic Violence and the Indian Diaspora in the United States." Indian Journal of Gender Studies 12(2\&3): 427-453

Agnew, Vijay

1995 Resisting Discrimination: Women from Asia, Africa, and the Caribbean and the Women's Movement in Canada. Toronto: University of Toronto Press.

1998a "Tensions in Providing Services to South Asian Victims of Wife Abuse in Toronto." Violence Against Women 4(2):153-179

1998b In Search of a Safe Place. Toronto: University of Toronto Press.

Aldama, J. Arturo (ed.)

2003 Violence and the Body. Bloomington: Indiana University Press.

Bancroft, Lundy

2002 Why Does he do That? New York: Berkley Books.

Bhanot, Surbhi

2002 South Asian Men's Attitudes Towards Violence Against Women: Are Gender Role Beliefs and Acculturation Important Factors. Thesis MA, University of Windsor.

Biao, Xiang

2005 Gender, Dowry and the Migration System of Indian Information Technology Professionals. Indian Journal of Gender Studies 12: 357

Brommer, JoAnne Stephanie

2004 "We Walk with Them": South Asian Women's Organizations in Northern California Confront Domestic Abuse. PhD Thesis, University of California.

Bulbeck, Chilla

1998 Re-Orienting Western Feminism: Women's Diversity in a Postcolonial World. Cambridge: Cambridge University Press.

Cohen, Lawrence

1998 No Aging in India: Alzheimer's, the Bad Family and Other Modern Things. Los Angeles: University of California Press. 
Collier, Cheryl N.

2008 "Neoliberalism and Violence Against Women: Can Retrenchment Convergence Explain the Path of Provincial Anti-Violence Policy, 1985-2005." Canadian Journal of Political Science 41(1):19-42

Crenshaw, Kimberle Williams

1994 "Mapping the Margins: Intersectionality, Identity Politics, and Violence Against Women of Color". Pp 93-118 in Martha Albertson Fineman, Rixanne Mykitiuk, (eds.) The Public Nature of Private Violence. New York: Routledge.

Dasgupta, Shamita Das

2000 "Charting the Course: An Overview of Domestic Violence in the South Asian Community in the United States." Journal of Social Distress and the Homeless 9(3): $173-185$

Davidson, Mark

2007 "Gentrification as Global Habitat: a Process of Class Formation or Corporate Creation?" Transactions of the Institute of British Geographers, 32(4): 490-506

Day, Shelagh and Gwen Brodsky

2007 "Women and the Canada Social Transfer:Securing the Social Union. Status of Women Canada.

http://www.fafia-afai.org/files/Day_brodskySWCMarch2007.pdf

Date Accessed: February 28, 2009

Desjarlais Robert and Arthur Kleinman

1997 "Violence and Well-Being." Social Science and Medicine 45(8): 1143-1145

Dhruvarajan, Vanaja and Jill Vickers

2002 Gender Race \& Nation. Toronto: University of Toronto Press.

Durazo, Ana Clarissa Rojas

2006 "The Medicalization of Domestic Violence." Pp. 179-191 in Color of Violence: The INCITE! Anthology. Cambridge: South End Press.

Evans, Patricia M.

2007 "(Not) Taking Account of Precarious Employment: Workfare Policies and Lone Mothers in Ontario and the UK." Social Policy and Administration 41(1):29-49

Farmer, Paul

2005 Pathologies of Power: Health, Human Rights and the New War on the Poor. Los Angeles: University of California Press.

Fishbach, Ruth L. and Barbara Herbert

1997 "Domestic Violence and Mental Health: Correlates and Conundrums Within and Across Cultures." Social Science and Medicine 45(8):1161-1176 
Friedric, Karin

2005 "Power Hegemony, and Gender-Based Violence in Northwestern Ecuador" Paper presented at the Society for Applied Anthropology, Sante Fe, New Mexico.

Friesen Joe

2010 "The Changing Face of Canada: Booming Minority Populations by 2031". Globe and Mail: March 9, 2010.

http://www.theglobeandmail.com/news/national/canadas-visible-minoritypopulation-to-nearly-double-by-2031/articlel494651/

Date Accessed: March 9, 2010

Gill, Aisha and Gulshan Rehman

2004 "Empowerment through Activism: Responding to Domestic Violence in the South Asian Community in London." Gender and Development 12(1):75-82

Goel, Rashmi

2005 "Sita's Trousseau: Restorative Justice, Domestic Violence, and South Asian Culture." Violence Against Women 11(5):639-665

Gupta, Sangeeta R. (ed.)

1999 Emerging Voices. Walnut Creek: AltaMira Press.

Gupta, Sangeeta R. (ed.)

1999 "Forged By Fire: Indian-American Women Reflect on their Marriages, Divorces and Rebuilding Lives.” Pp. 193-221 in Sangeeta R. Gupta (ed.) Emerging Voices. Walnut Creek: AltaMira Press.

Harvey, David

2005 A Brief History of Neoliberalism. New York: Oxford University Press.

Hunjan, Sandeep

2003 South Asian Women in Canada: Experiences of Intimate Partner Violence. $\mathrm{PhD}$ Thesis, University of Windsor.

Javed, Noor and Nicholas Keung

2008 "Visible Minorities Gaining". The Toronto Star: April 3, 2008 http://www.thestar.com/Canada/Census/article/409455

Date Accessed: April 3, 2008

Jiwani, Yasmin

2002a "The 1999 General Social Survey on Spousal Violence: An Analysis." Pp 63-73 in Katherine McKenna and June Larkin (eds.) Violence Against Women: New Canadian Perspectives. Toronto: Inanna Publications. 
2002b "Race, Gender, Violence and Health Care." Pp 223-254 in Katherine McKenna and June Larkin (eds.) Violence Against Women: New Canadian Perspectives. Toronto: Inanna Publications.

2006 Discourses of Denial: Mediations of Race, Gender and Violence. Vancouver: UBC Press.

Kabeer Naila

1999 "Resources, Agency, Acheivements: Reflections on the Measurement of Women's Empowerment". Development and Change 30: 435-464.

Kleinman, Arthur

2000 Violences of Everyday Life: The Multiple Forms and Dynamics of Social Violence". Pp. 226-241 in Veena Das, Arthur Kleiman, Mamphela Ramphele and Pamela Reynolds (eds.), Violence and Subjectivity. Berkeley: University of California Press

Koyama, Emi

2006 "Disloyal to Feminism: Abuse Survivors within the Domestic Violence Shelter System." Pp. 208-222 in Color of Violence: The INCITE! Anthology. Cambridge: South End Press.

Krishnan, P Satya, Malahat Baig-Amin, Louisa Gilbert, Nbila El-Bassel and Anne Waters

1998 "Lifting the Veil of Secrecy: Domestic Violence Against South Asian Women in the United States". Pp. 145-159 in Shamita Das Dasgupta (ed.), A Patchwork Shawl: Chronicles of South Asian Women in America. New Brunswick: Rutgers University Press.

Ley, David and Heather Smith

2000 "Relations Between Deprivation and Immigrant Groups in Large Canadian Cities." Urban Cities 37(1): 37-62

McKenna, Katherine and June Larkin (eds.)

2002 Violence Against Women: New Canadian Perspectives. Toronto: Inanna Publications.

McLeod, Linda and Maria Shin

1992 Isolated, Afraid and Forgotten: The Service Delivery Needs and Realities of Immigrant and Refugee Women Who Are Battered. National Clearing House on Family Violence. Ottawa: Public Health Agency of Canada http://www.phac-aspc.gc.ca/ncfv-cnivf/familyviolence/pdfs/isolatedafraid.pdf Date Accessed: February 28, 2009 
Mehrotra, Meeta

1999 "The Social Construction of Wife Abuse - Experiences of Asian Indian Women in the United States." Violence Against Women 5(6):619-640

Merchant, Munira

2000 "Comparative Study of Agencies Assisting Domestic Violence Victims: Does the South Asian Community Have Special Needs?' Journal of Social Distress and the Homeless 9(3):249-259

Mihorean, Karen, Sandra Besserer, Dianne Hendrick, Jodi-Anne Brzozowski, Catherine Trainor and Stacie Ogg

2001 A Profile of Criminal Victimization: Results of the 1999 General Social Survey. Ottawa: Canadian Centre for Justice Statistics. http:/www.statcan.gc.ca/pub/85-553-x/85-553-x1999001-eng.pdf

Date Accessed: February 23, 2010

Morrow, Marina, Olean Hankivsky and Colleen Varcoe

2004 "Women and Violence: the Effects of Dismantling the Welfare State." Critical Social Policy 24(3):358-384

Narayan, Uma

1990 "The Project of Feminist Epistemology: Perspectives from a Nonwestern Feminist." Pp 256-72 in A. Jaggar and S. Bordo (eds.), Gender/Body/Knowledge: Feminist Reconstructions of Being and Knowing. New Brunswick: NJ Rutgers University Press.

Ogrodnik, Lucie

2009 Family Violence in Canada: A Statistical Profile. Ottawa: Canadian Centre for Justice Statistics.

http:/www.statcan.gc.ca/pub/85-224-x/85-224-x2009000-eng.pdf

Date Accessed: February 23, 2010

Palriwala, Rajni and Patricia Uberoi

2005 "Marriage and Migration in Asia: Gender Issues." Indian Journal of Gender Studies 12(2\&3): v-xxix

Peacock, Sunita

2003 "Sita's War and the Body Politic." Pp. 360-374 in J. Arturo Aldama (ed.)

Violence and the Body. Bloomington: Indiana University Press

Rahim, Habibeh

2000 "Virtue, Gender and the Family: Reflections on Religious Texts in Islam and Hinduism." Journal of Social Distress and the Homeless 9(3): 187-199 
Raj, Anita and Jay G. Silverman

2003 "Immigrant South Asian Women at a Greater Risk for Injury from Intimate Partner Violence." American Journal of Public Health 93(3): 435-436

Ranga Rao, A.B.S.V. and Sekhar K.

2002 "Divorce: Process and Correlates a Cross-Cultural Study." Journal of Comparative Family Studies 33(4):541-563

Rigger, Stephanie and Susan L. Staggs

2004 "Welfare Reform, Domestic Violence, and Employment: What Do We Know and What Do We Need to Know?" Violence Against Women 10(9):961-990.

Sahota, Puneet Kaur Chawla

2006 "The Personal is the Private is the Cultural." Pp. 231-242 in Color of Violence: The INCITE! Anthology. Cambridge: South End Press.

Sheel, Ranjana

2005 "Marriage, Money and Gender: A Case Study of the Migrant Indian Community in Canada." Indian Journal of Gender Studies 12(2\&3): 335-356

Shiwadkar, Swati

2004 "Canadian Domestic Violence Policy and Indian Immigrant Women." Violence Against Women 10(8):860-879

Singer, Merrill, Freddie Valentin, Hans Baer and Zhongke Jia.

1998 "Why Does Juan Garcia Have a Drinking Problem? The Perspective of Critical Medical Anthropology." Pp. 286-302 in Peter J. Brown (ed.) Understanding and Applying Medical Anthropology. Mountain View: Mayfield Publishing Company.

Slater, Tom

2004 "Municipally Managed Gentrification in South Parkdale, Toronto." The Canadian Geographer 48(3):303-325.

Subrahmanyan, Lalita

1999 "A Generation in Transition: Gender Ideology of Graduate Students from India at an American University" Pp. 58-78 in Sangeeta R. Gupta (ed.) Emerging Voices. Walnut Creek: AltaMira Press.

Sudbury, Julia

2006 "Rethinking Violence Strategies: Lessons from the Black Women's Movement in Britain" Pp. 13-24 in Color of Violence: The INCITE! Anthology. Cambridge: South End Press. 
Teelucksingh, Cheryl and Grace-Edward Galabuzi

2005 Working Precariously: The Impact of Race and Immigrant Status on Employment Opportunities and Outcomes in Canada. Toronto: The Canadian Race Relations Foundation.

Thiara, Ravi K

2010 "Continuing Control: Child Contact and Post-Separation Violence." Pp. 156-181 in Ravi K. Thiara and Aisha K. Gill (eds). Violence Against Women in South Asian Communities: Issues for Policy and Practice. London: Jessica Kingsley Publishers.

Thiara, Ravi K. and Aisha K. Gill eds.

2010a Violence Against Women in South Asian Communities: Issues for Policy and Practice. London: Jessica Kingsley Publishers.

$2010 \mathrm{~b}$ "Introduction." Pp. 29-55 in Ravi K. Thiara and Aisha K. Gill eds. Violence Against Women in South Asian Communities: Issues for Policy and Practice. London: Jessica Kingsley Publishers.

2010c "Understanding Violence Against South Asian Women: What it Means for Practice." Pp. 29-55 in Ravi K. Thiara and Aisha K. Gill eds. Violence Against Women in South Asian Communities: Issues for Policy and Practice. London: Jessica Kingsley Publishers.

Tjaden, Patricia

2004 "What Is Violence Against Women? Defining and Measuring the Problem: A Response to Dean Kilpatrick." Journal of Interpersonal Violence 19(11): 12441251

Tolman, Richard M. and Daniel Rosen

2001 "Domestic Violence in the Lives of Women Receiving Welfare: Mental Health, Substance Dependence, and Economic Well-Being". Violence Against Women $7(2): 141-158$

Tutty, Leslie

1999 Husband Abuse: An Overview of Research and Perspectives. Family Violence Prevention Unit, Health Canada. http://www.phac-aspc.ge.ca/ncfv-cnivf/familyviolence/pdfs/husbandenglish.pdf Date Accessed: February 28, 2009

Wachholz, Sandra and Baukje Meidema

2000 "Risk, Fear, Harm: Immigrant Women's Perceptions of the "Policing Solution" to Woman Abuse". Crime, Law and Social Change 34: 301-317

West, Traci C.

2006 "An Antiracist Christian Ethical Approach to Violence Resistance" Pp. 243-249 in Color of Violence: The INCITE! Anthology. Cambridge: South End Press. 